\title{
PATHWAYS TO THE MARINE REALM IN SERPENTES
}




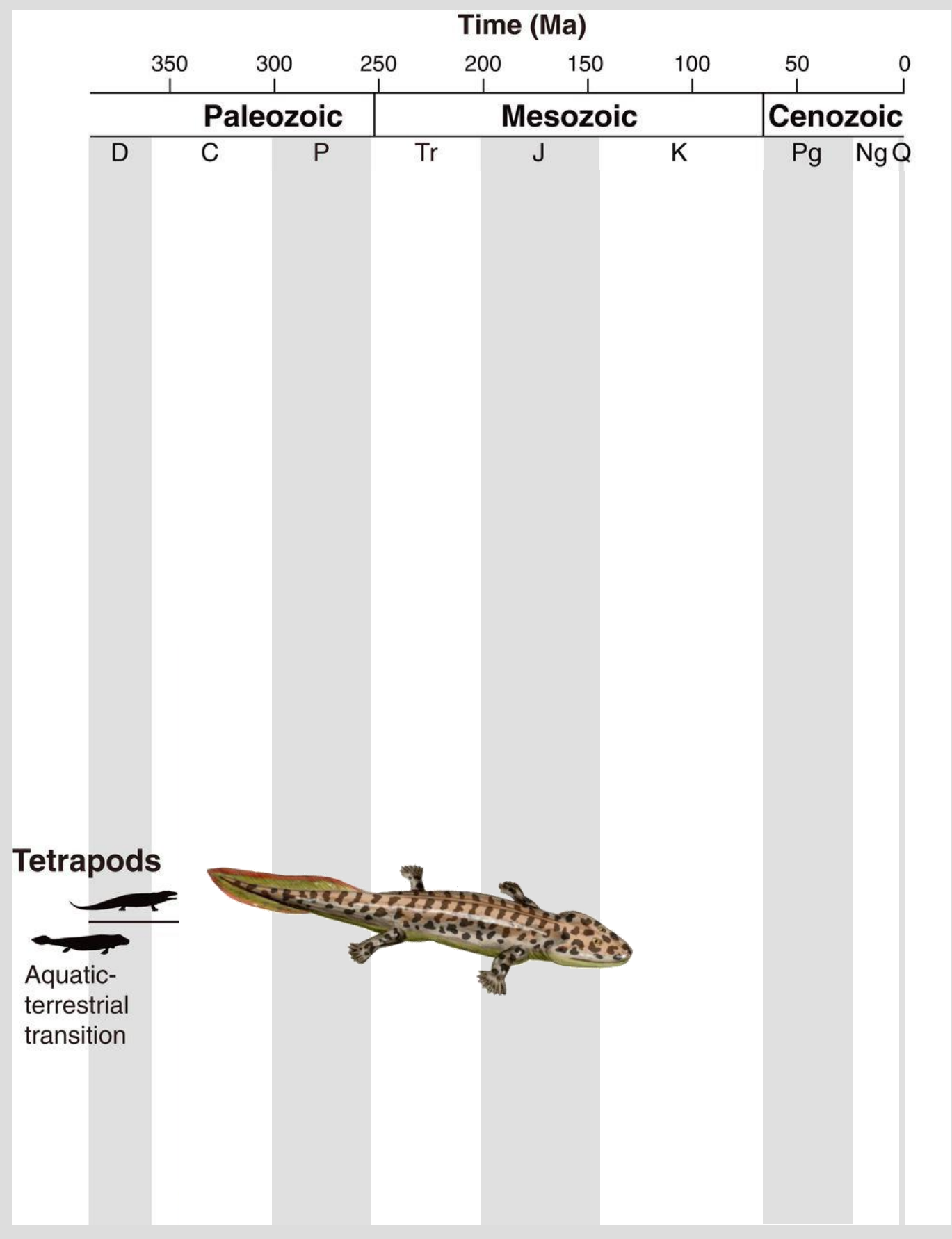



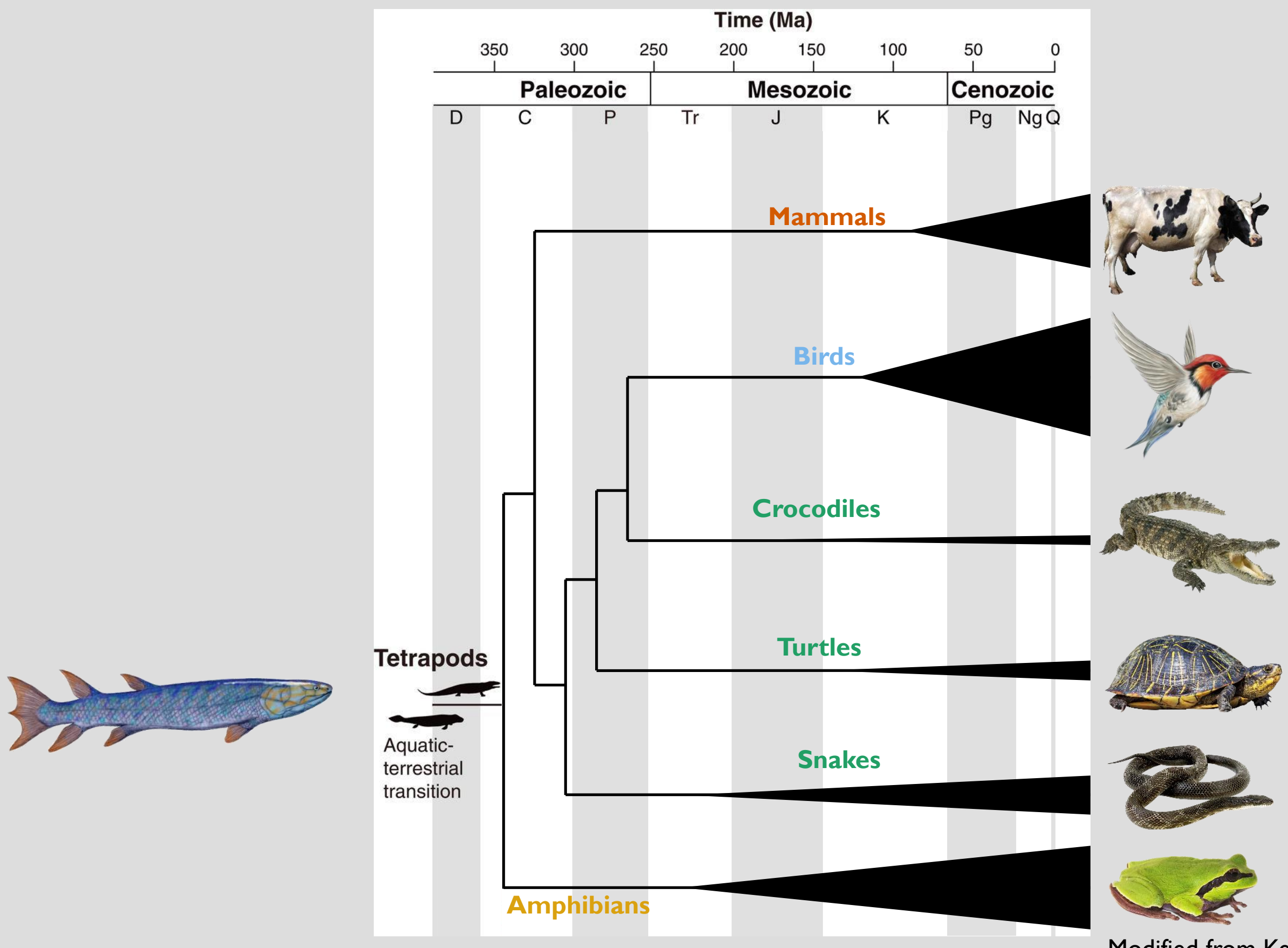

Modified from Kelley and Pyenson 20I5, Science 


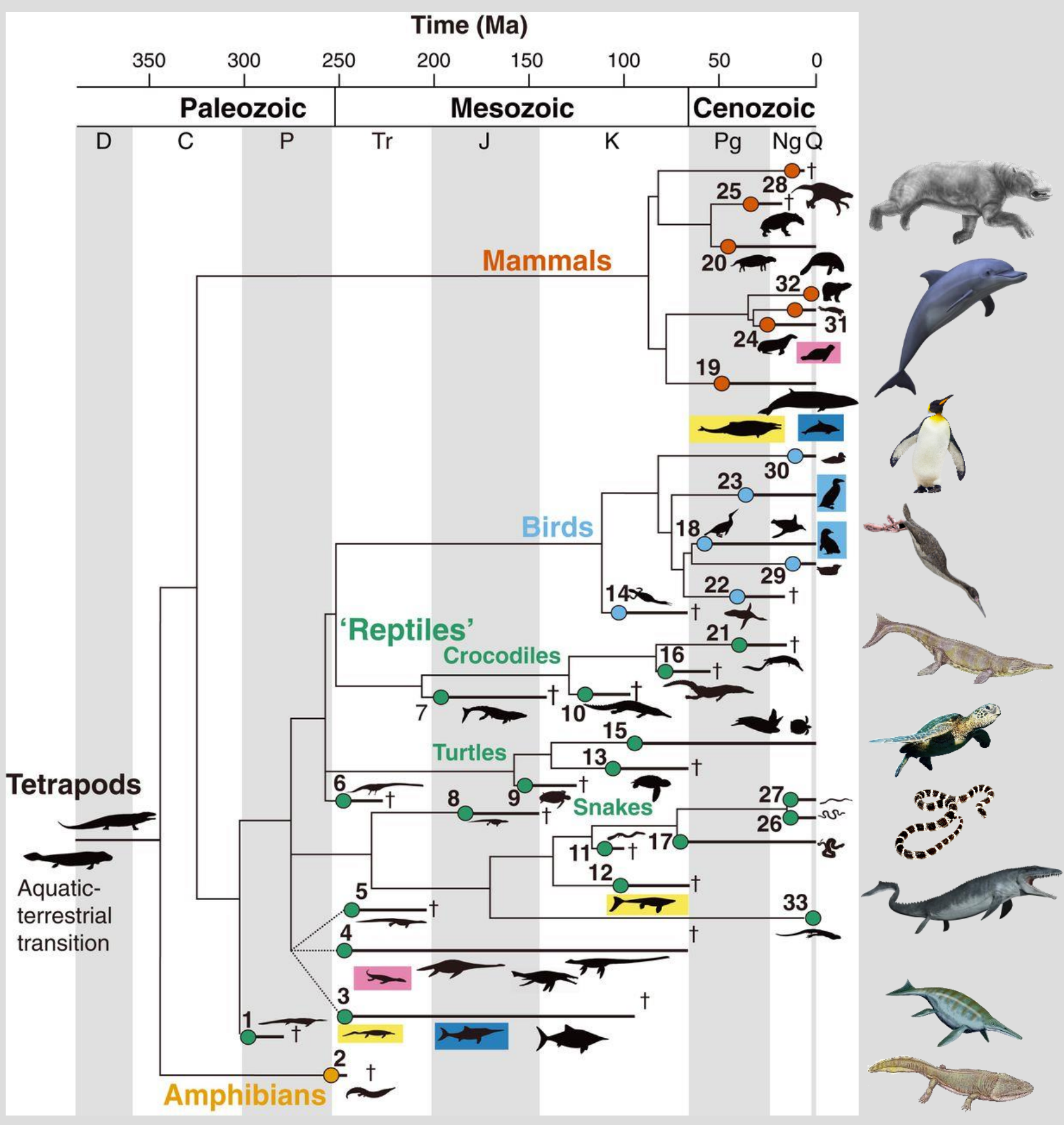

Kelley and Pyenson 2015, Science 


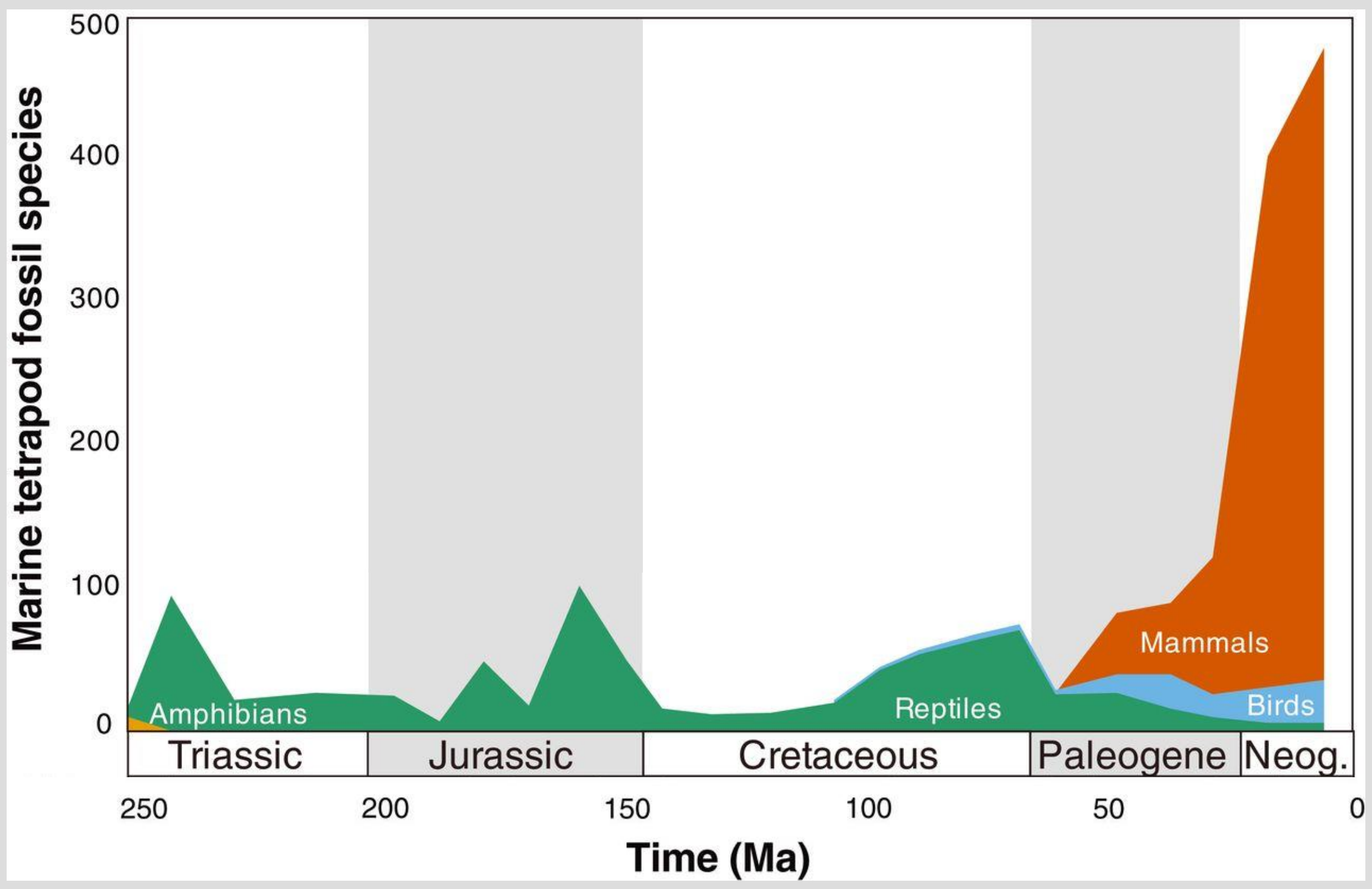

Modified from Kelley and Pyenson 2015, Science 


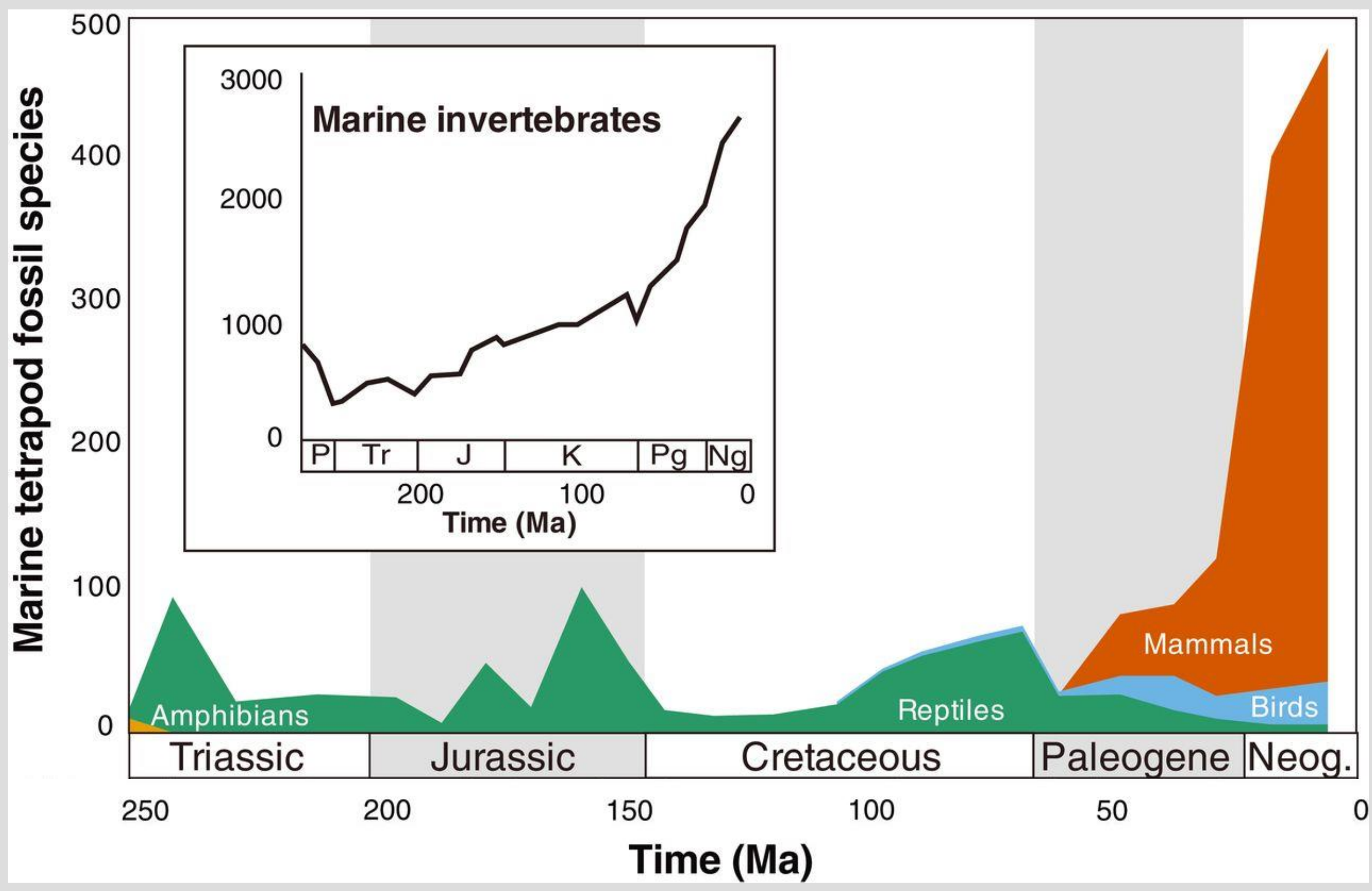




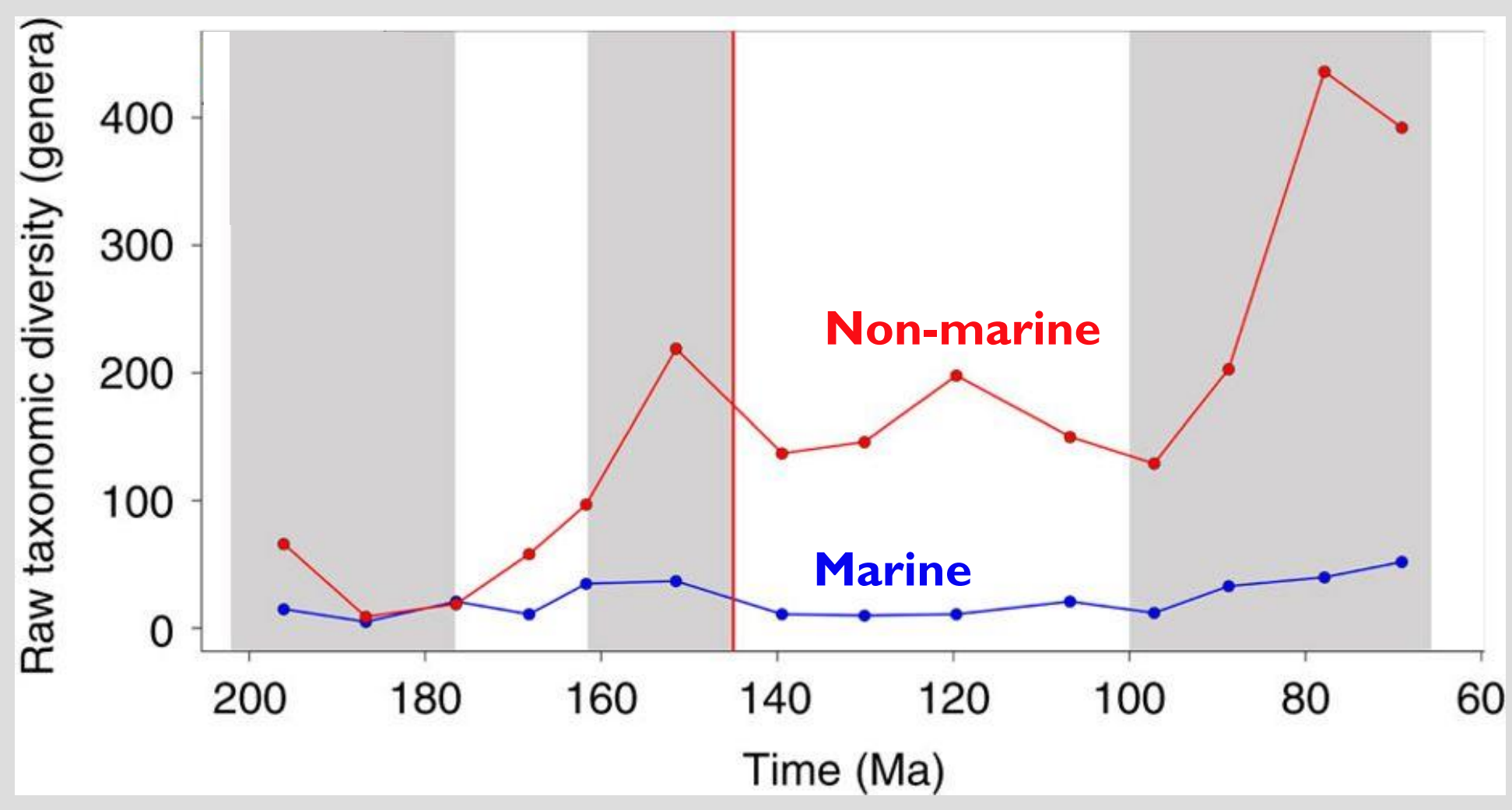

Modified from Tennant et al 2016, Nature Communications
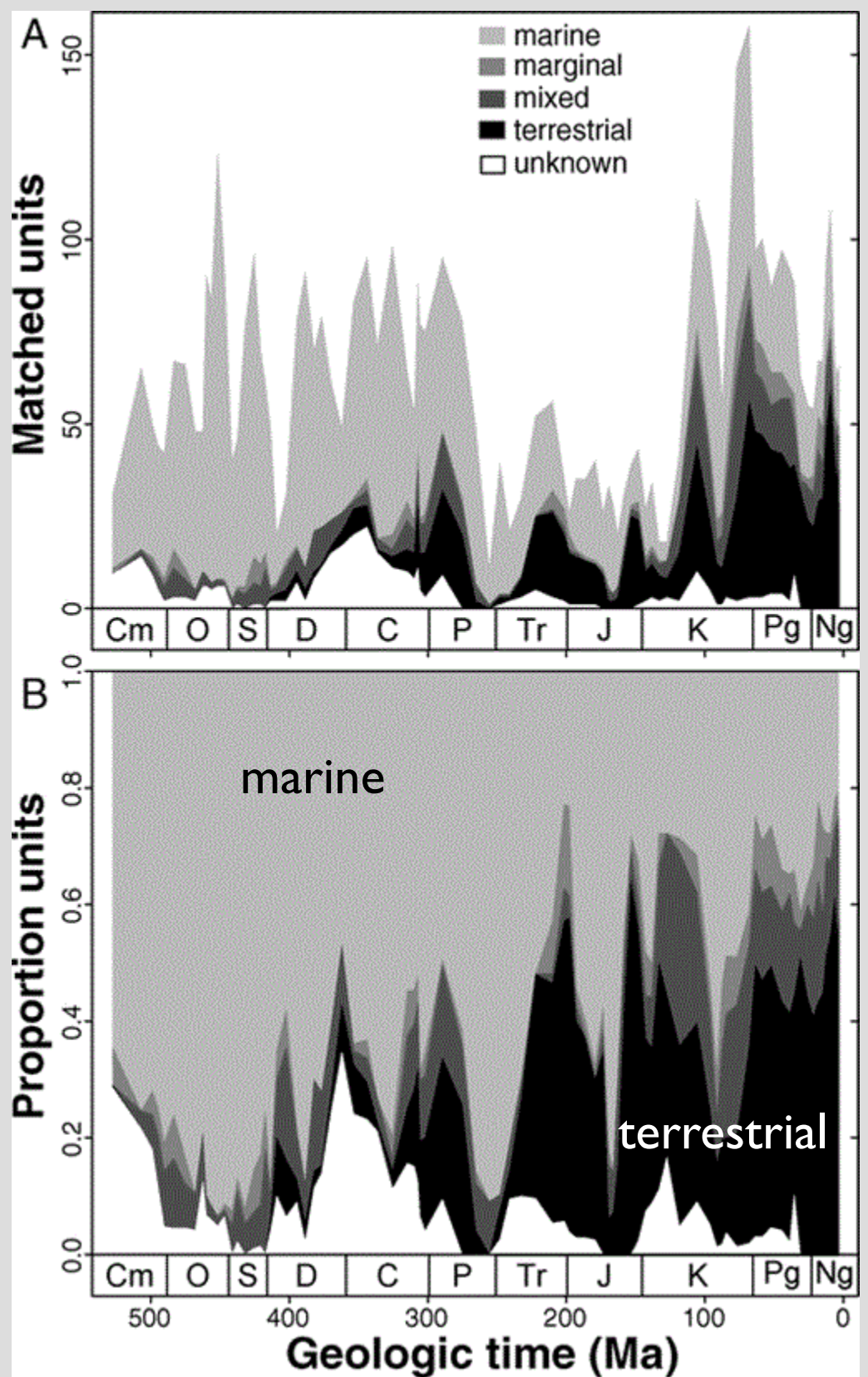

Peters and Heim 2010, Paleobiology 

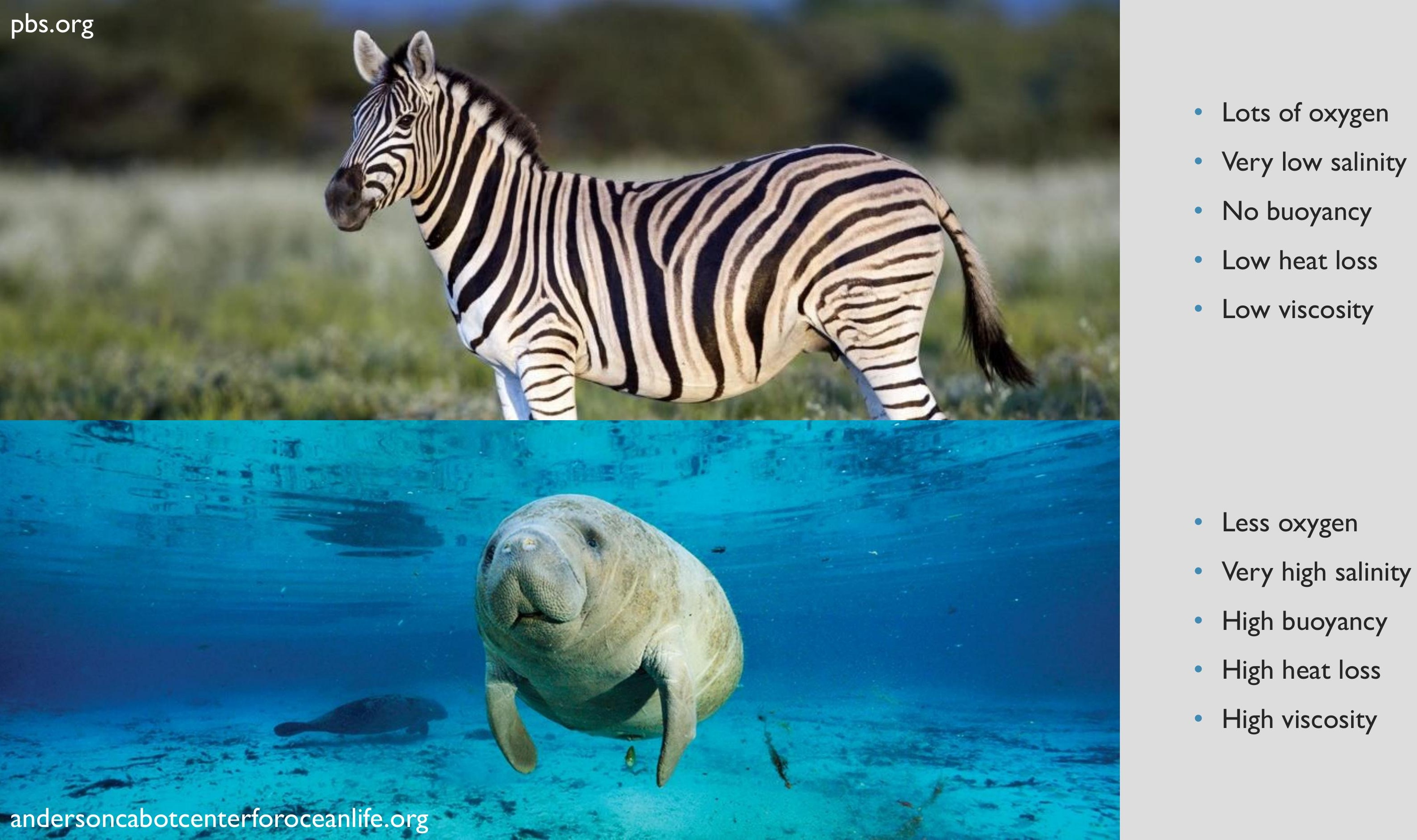

- Less oxygen

- Very high salinity

- High buoyancy

- High heat loss

- High viscosity 


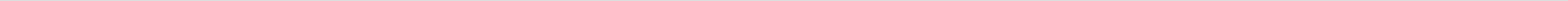




\section{PERMANENT LIFE IN THE OCEAN IS HARD*}

*WHEN YOU'VE ADAPTED TO LIVING ON LAND 


\section{SALT BALANCE}

ACQUISITION

THERMOREGULATION

PERMANENT LIFE IN THE OCEAN IS HARD*

*WHEN YOU'VE ADAPTED TO LIVING ON LAND

\section{DEHYDRATION}

\section{LOCOMOTION}

\section{REPRODUCTION}




\section{MAMMALS GET MUCH BIGGER}

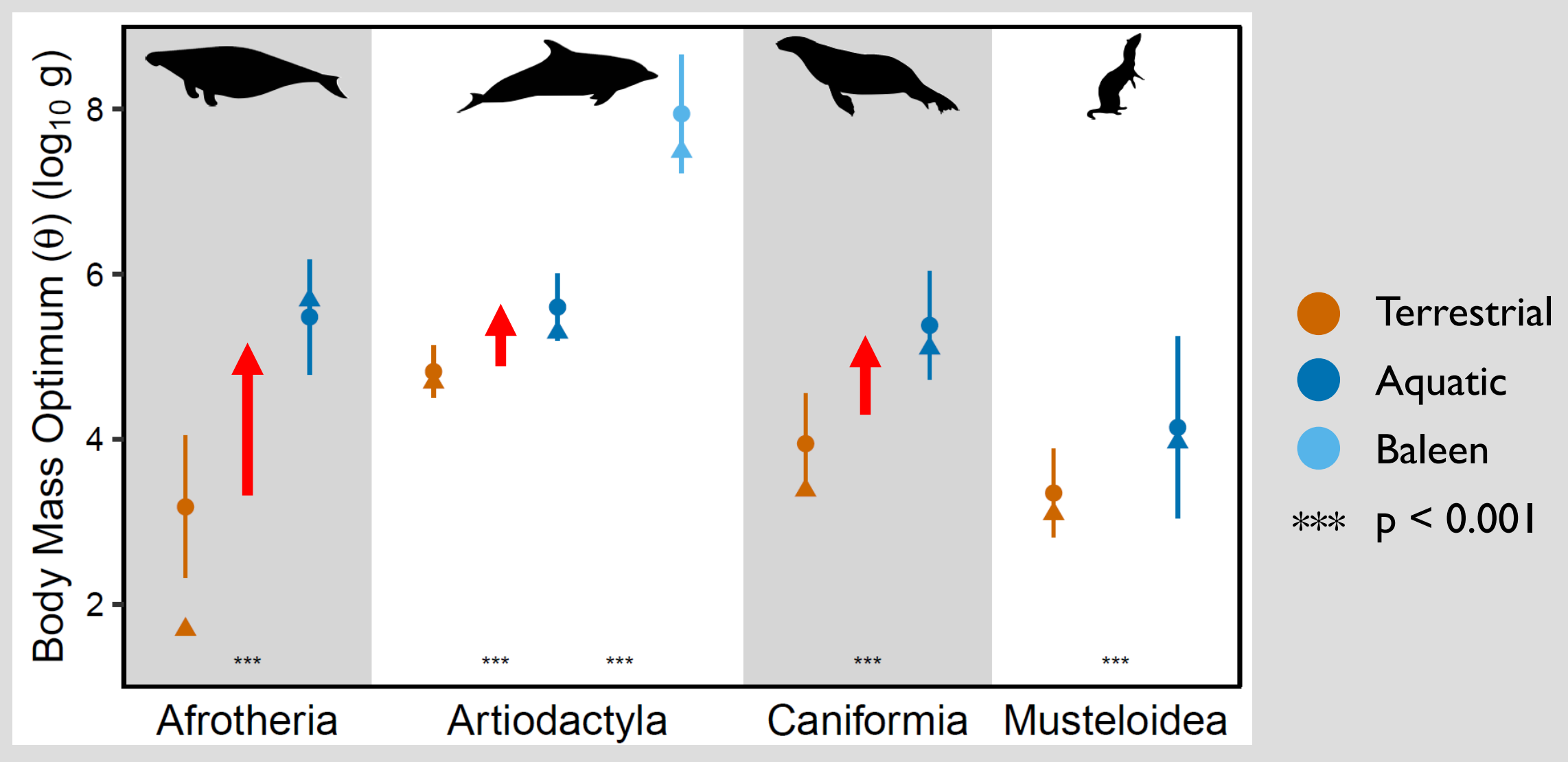




\section{CROCS GET MUCH BIGGER TOO}

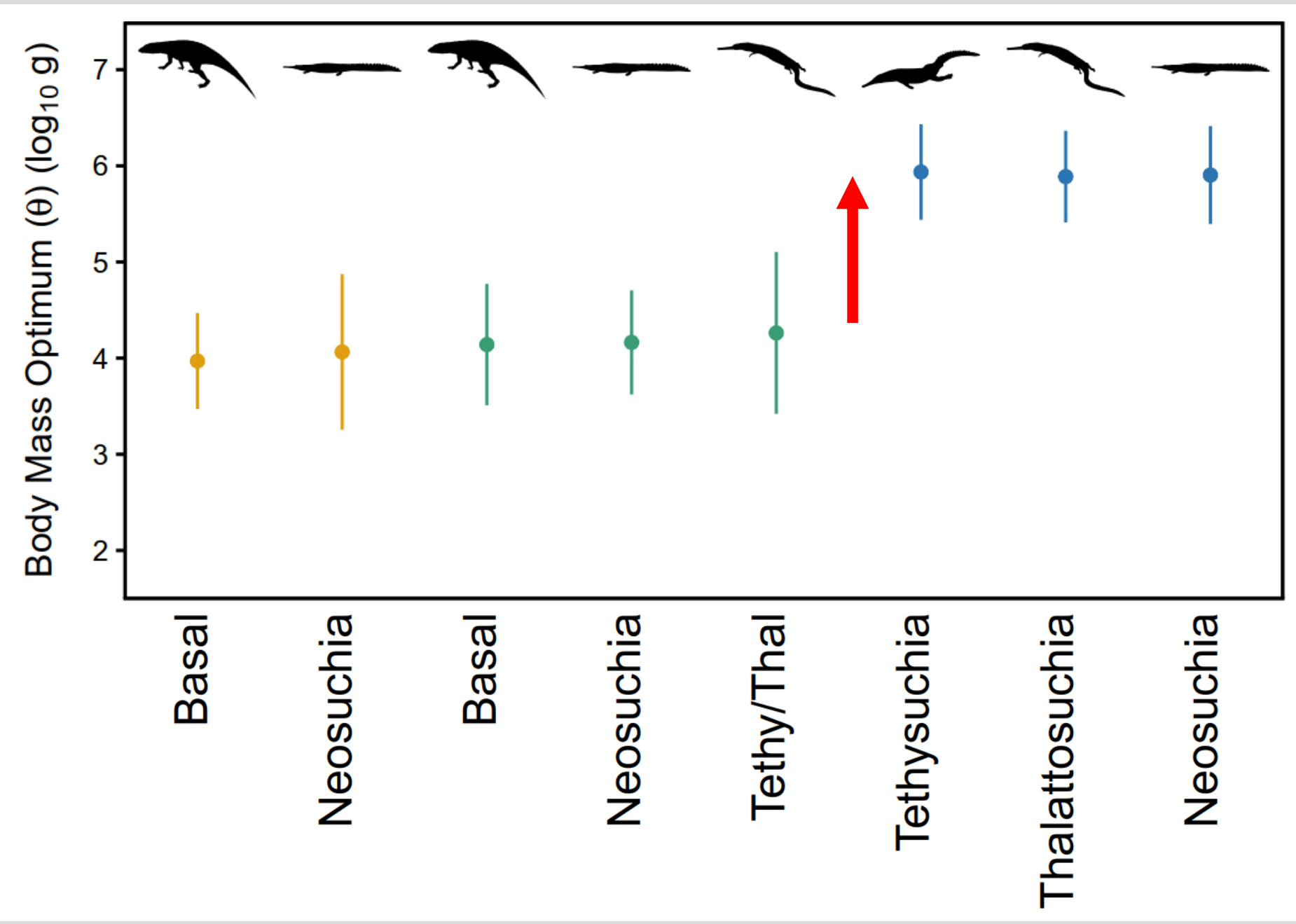

Terrestrial

Semi-aquatic

Marine 

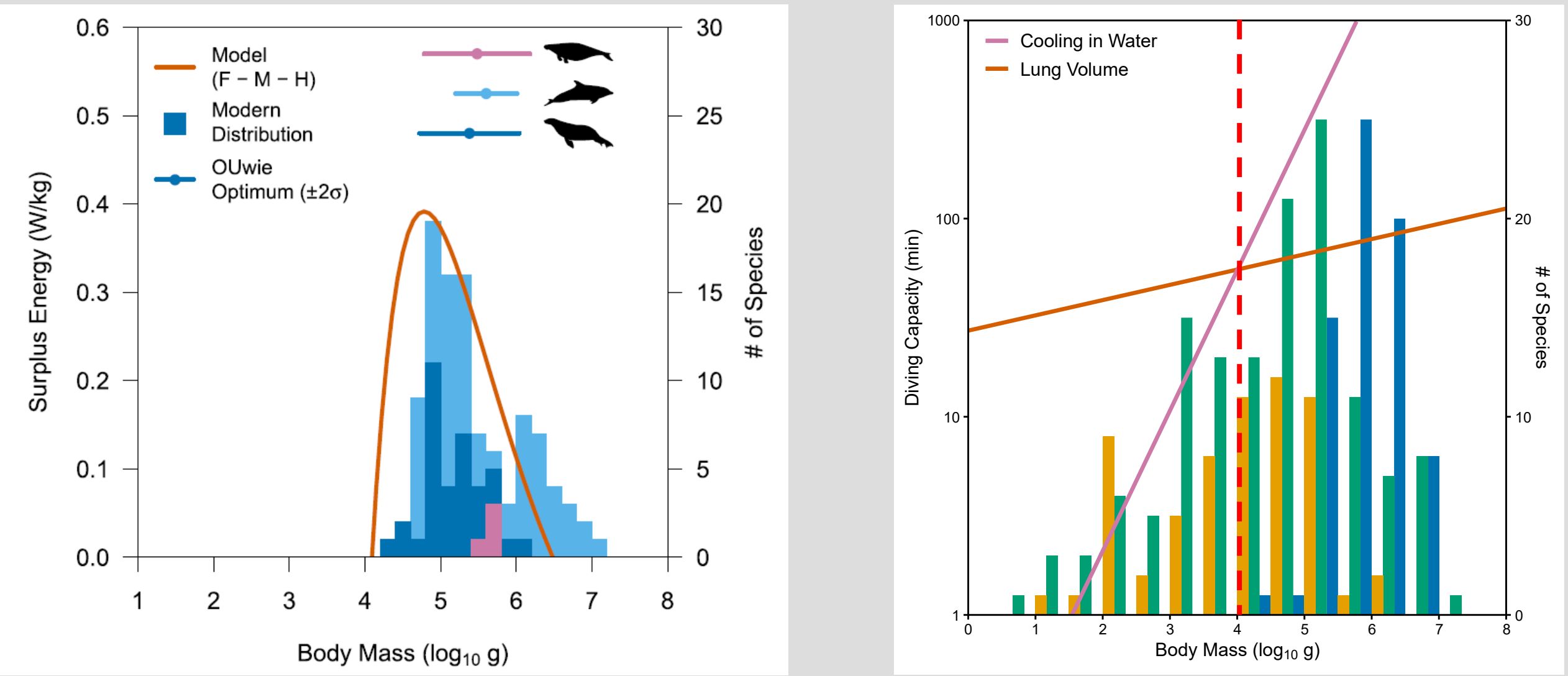

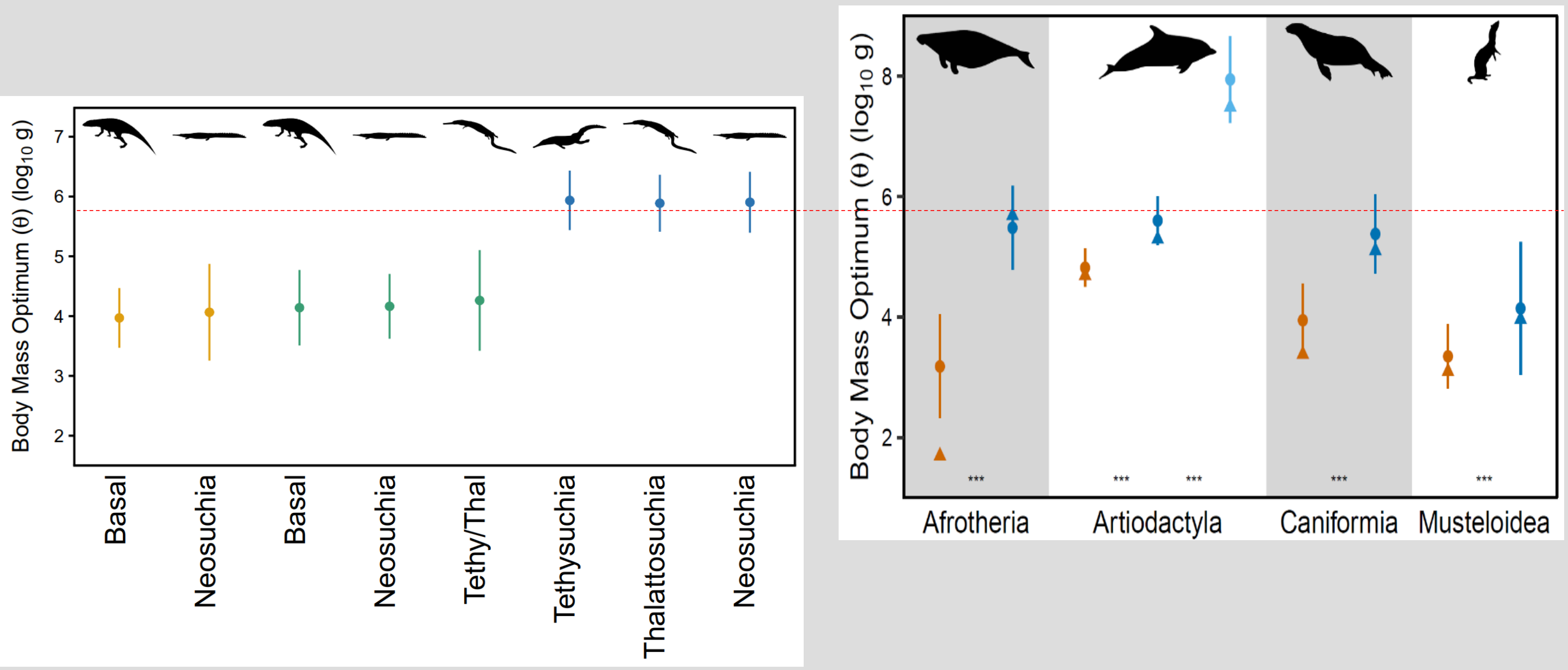

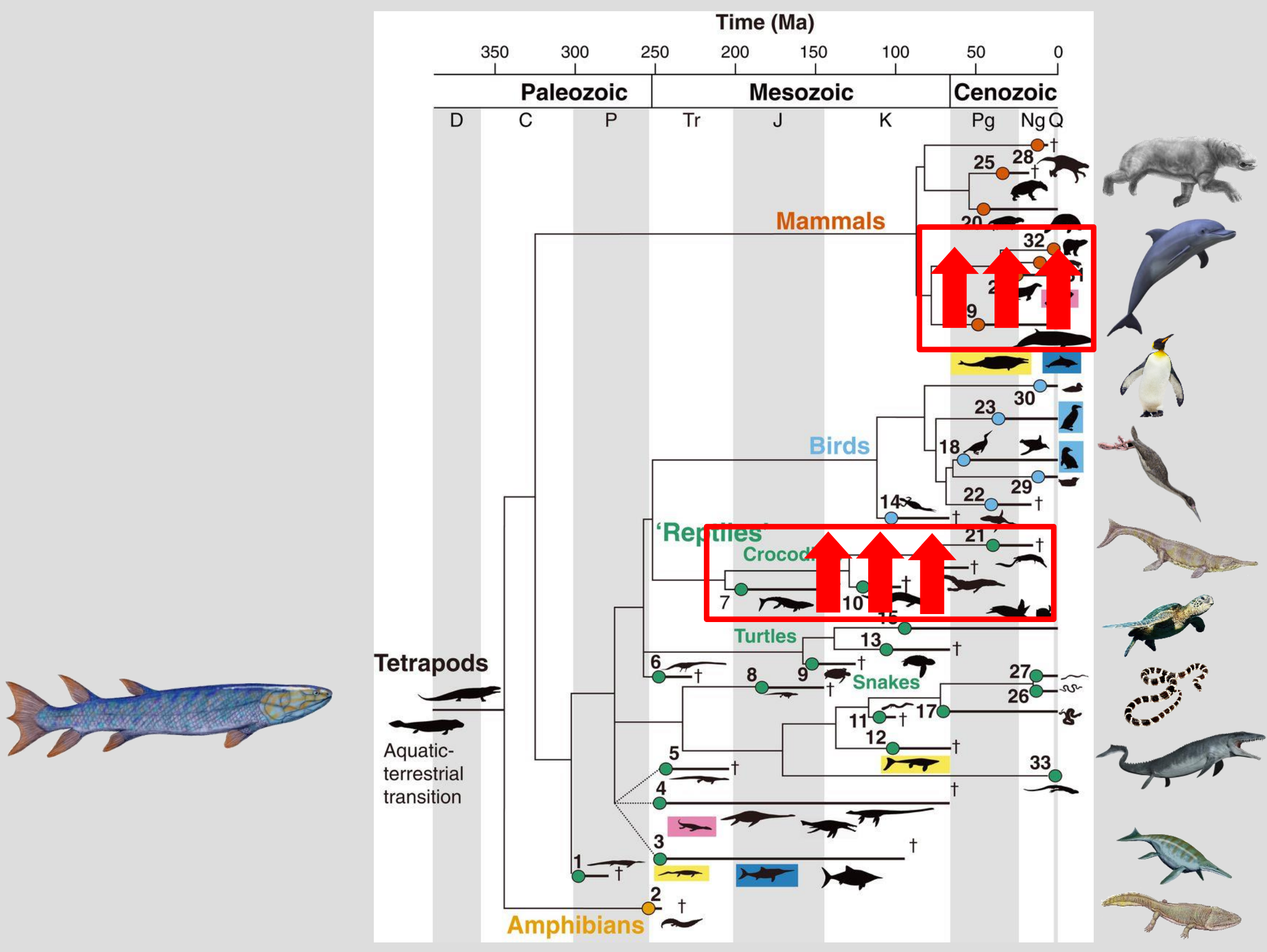

Amphibians $\sim$

Kelley and Pyenson 20I5, Science 


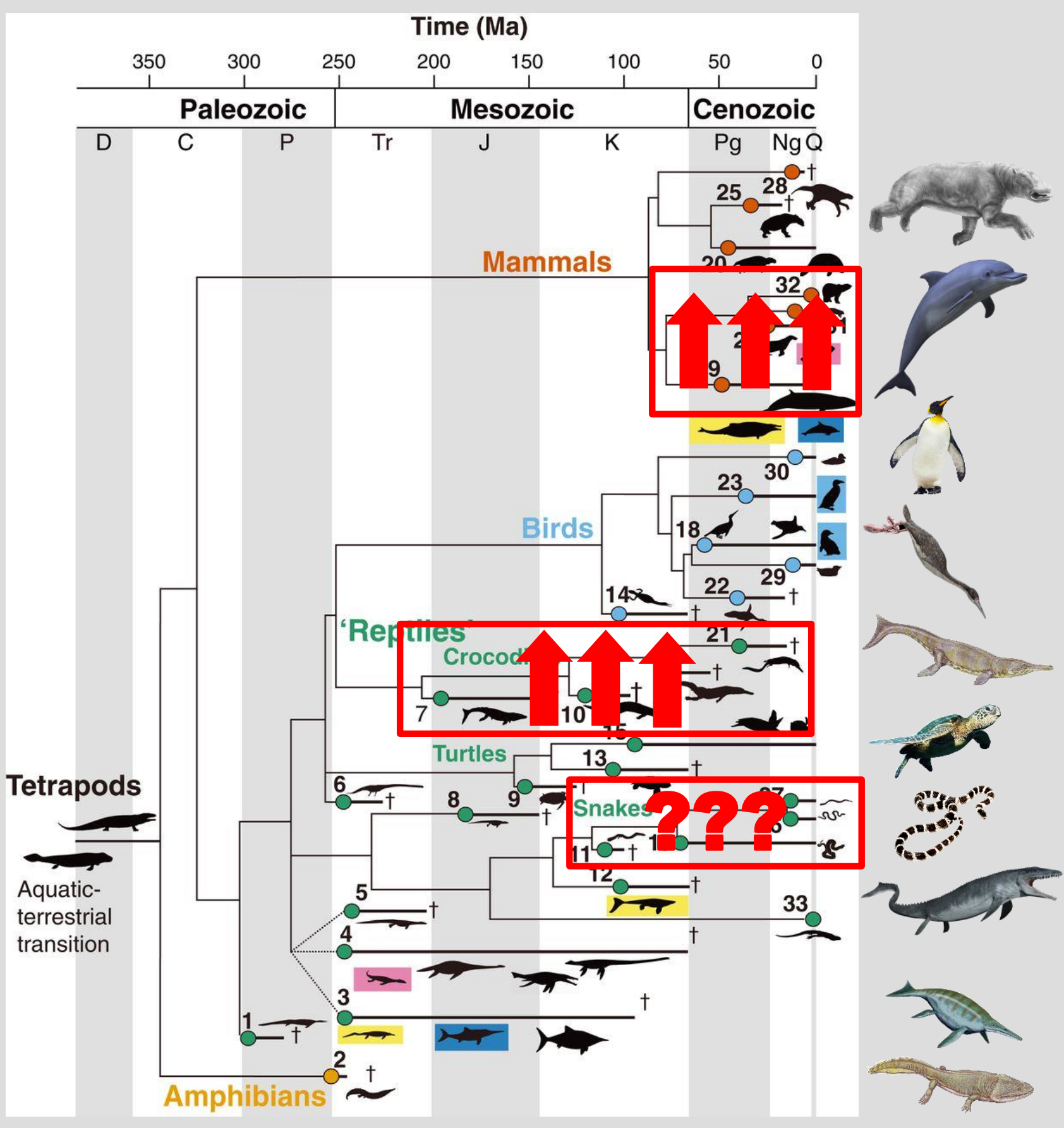

Kelley and Pyenson 2015, Science 


\section{SNAKES}
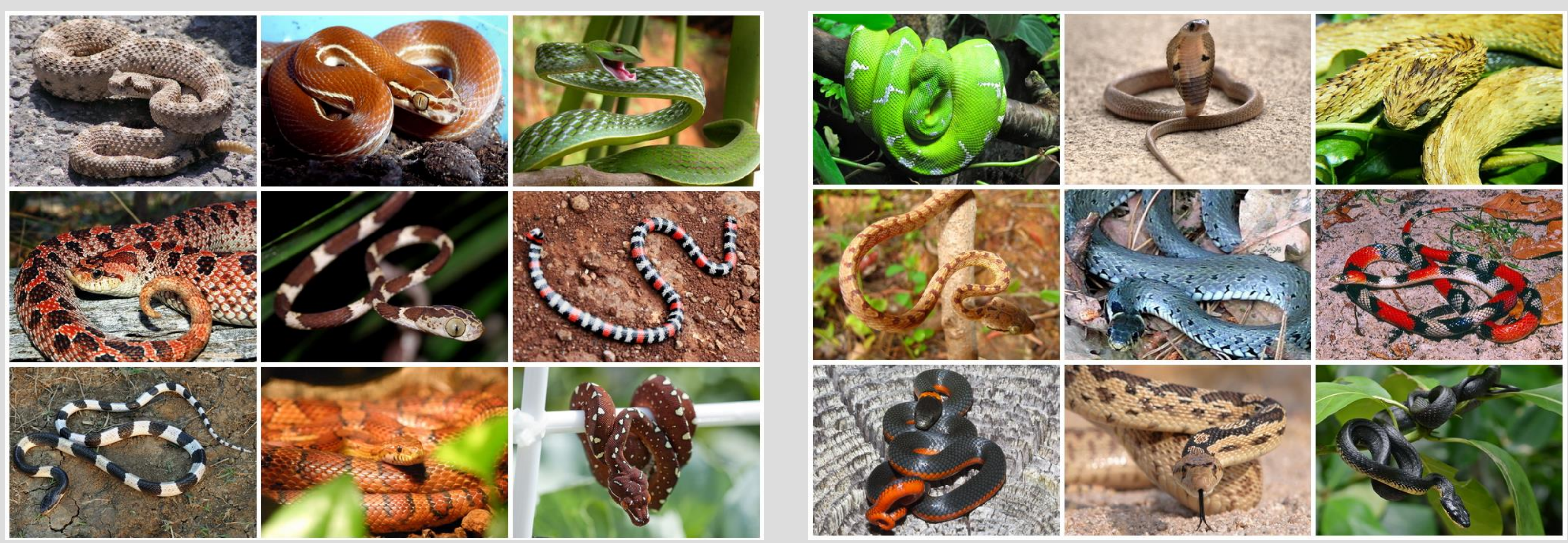


\section{PREVIOUS WORK}

Fully-sampled phylogenies of squamates reveal evolutionary patterns in threat status

João Filipe Riva Tonini ${ }^{\mathrm{a}, *}$, Karen H. Beard $^{\mathrm{b}}$, Rodrigo Barbosa Ferreira ${ }^{\mathrm{b}, \mathrm{c}}$, Walter Jetz $^{\mathrm{d}}$, R. Alexander Pyron ${ }^{\mathrm{a}}$

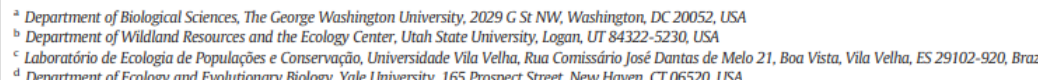

Global Ecology and Biogeography, (Global Ecol. Biogeogrr) (2016) 25, 187-197

RESEARCH Body sizes and diversification rates of lizards, snakes, amphisbaenians and the tuatara

Anat Feldman ${ }^{1}$, Niv Sabath ${ }^{2}$, R. Alexander Pyron ${ }^{3}$, Itay Mayrose ${ }^{2}$ and Shai Meirit

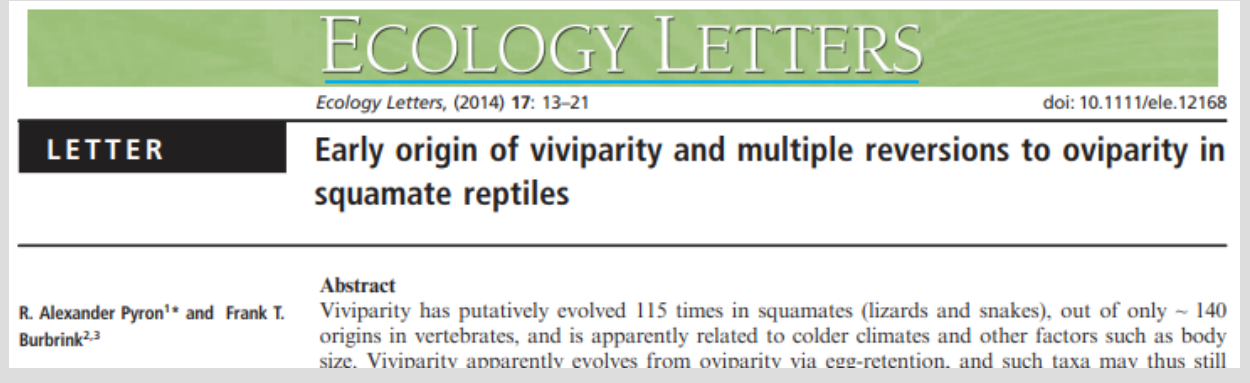
Global Ecology and Biogeography, (Global Ecol. Biogeogr) (2015) 24, 1433-1442

RESEARCH The geography of snake reproductive

\section{of snake viviparity}

Anat Feldman ${ }^{1 *}$, Aaron M. Bauer', Fernando Castro-Herrera

Laurent Chirio, Indraneil Das, Tiffany M. Doan', Erez Maza',

Danny Meirte ${ }^{7}$, Cristiano de Campos Nogueira, ${ }^{8}$, Zoltán Tamás Nagy"

Omar Torres-Carvajal ${ }^{10}$, Peter Uetz" ${ }^{11}$ and Shai Meiri
- Phylogeny $\Rightarrow$ Timescaled with ape::chronos() with fossil calibrations

- Body mass (g)

- Reproductive mode (eggs vs. live birth)

- Reproductive mode (eggs vs. live birth)

- Average temperature

- Average elevation 


\section{HABITAT DATA COLLECTION}

\section{BIOME}

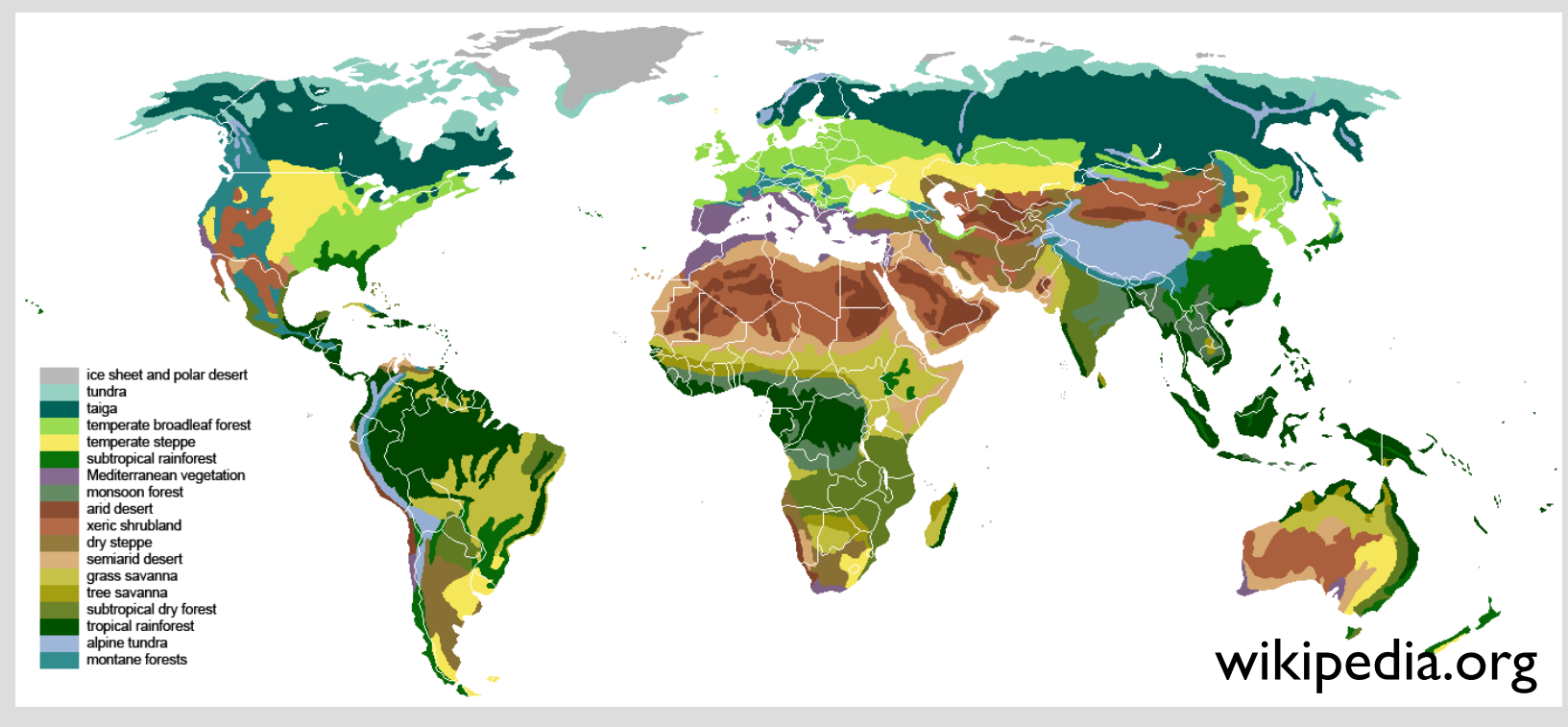

\section{TIERING}
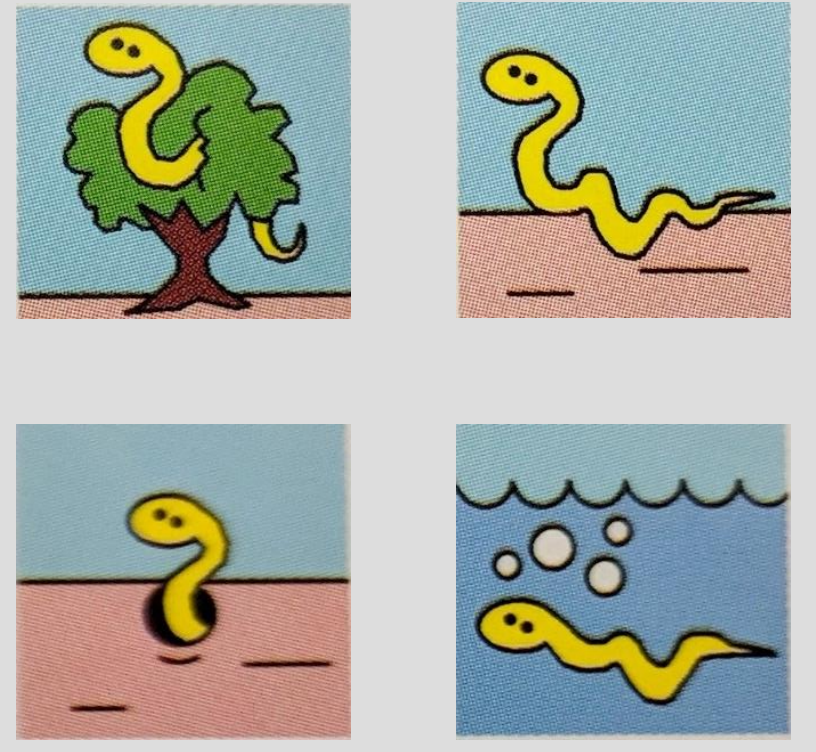

Marques, Eterovic, and Sazima 2012 


\section{HABITAT DATA COLLECTION}

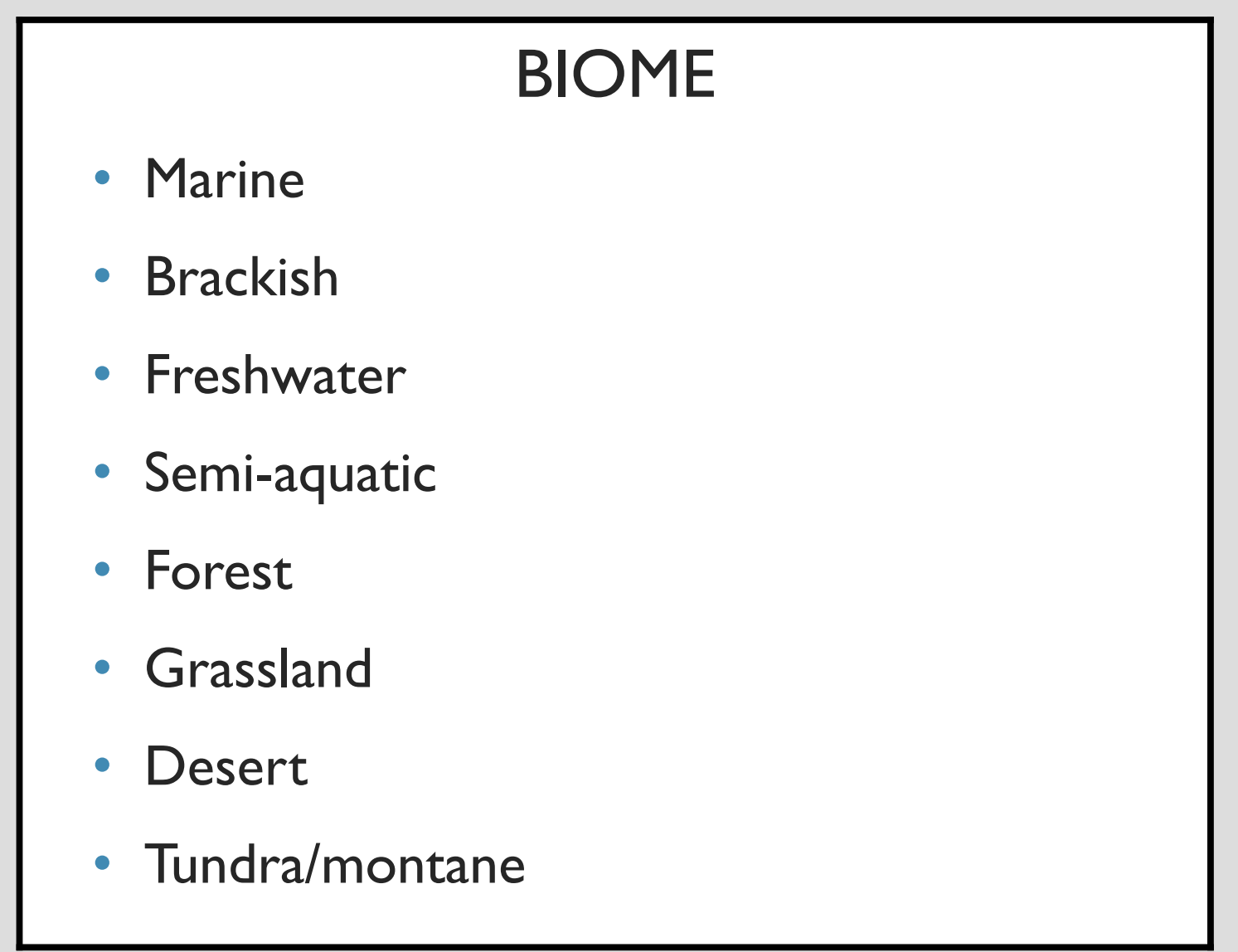

\section{TIERING}

- Arboreal

- Scansorial ("semi-arboreal” or "climber)

- Surficial ("terrestrial”)

- Semi-fossorial (occasional diggers)

- Fossorial (“digger”)

- Aquatic 


\section{HABITAT DATA COLLECTION}

BIOME
- Marine
- Brackish
- Freshwater
- Semi-aquatic
- Forest
- Grassland
- Desert
- Tundra/montane

\section{TIERING}

- Arboreal

- Scansorial ("semi-arboreal" or "climber)

- Surficial ("terrestrial”)

- Semi-fossorial (occasional diggers)

- Fossorial (“digger”)

- Aquatic 


\section{BODY SIZE BY BIOME}

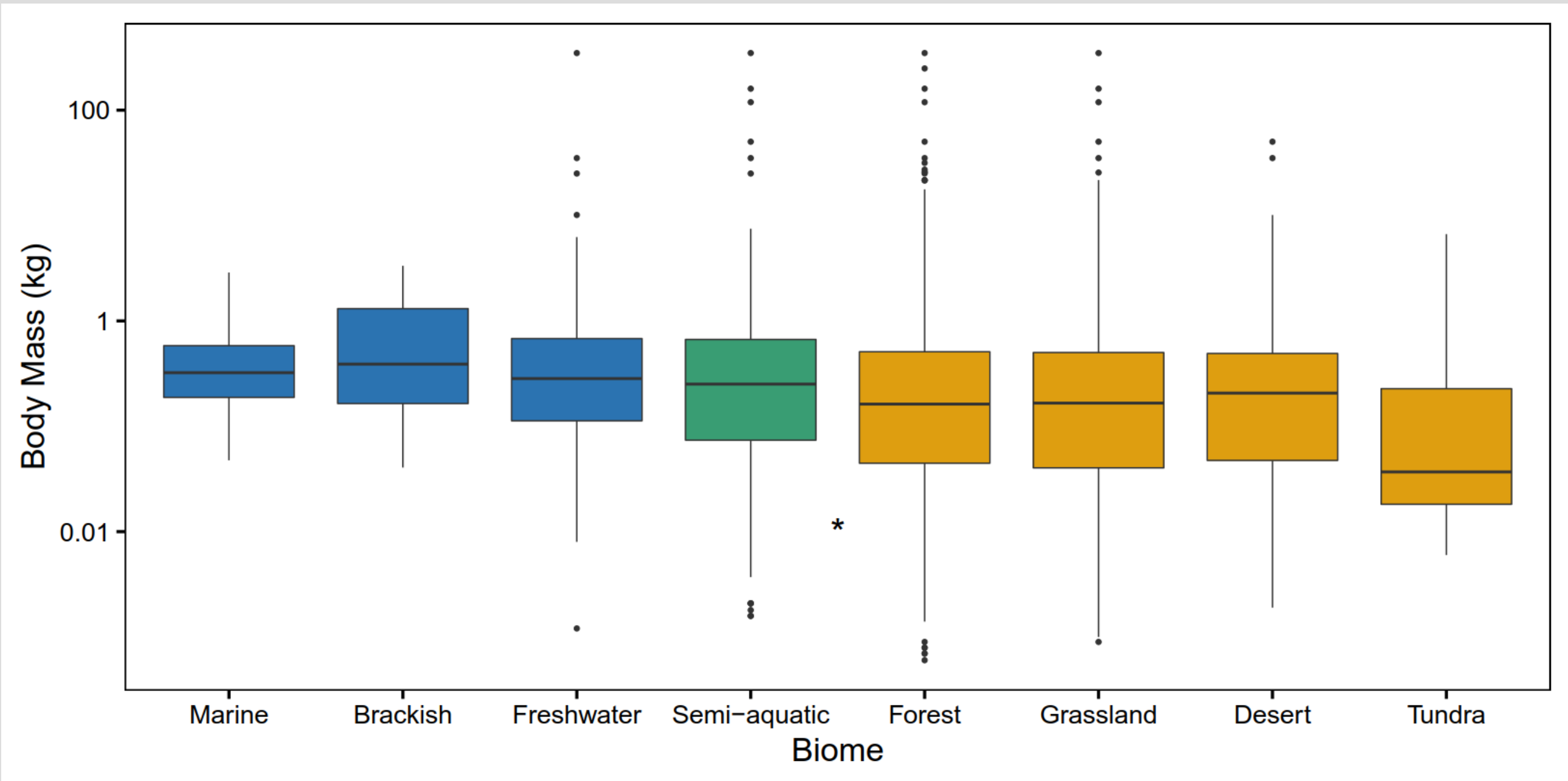




\section{TEMPERATURE BY BIOME}

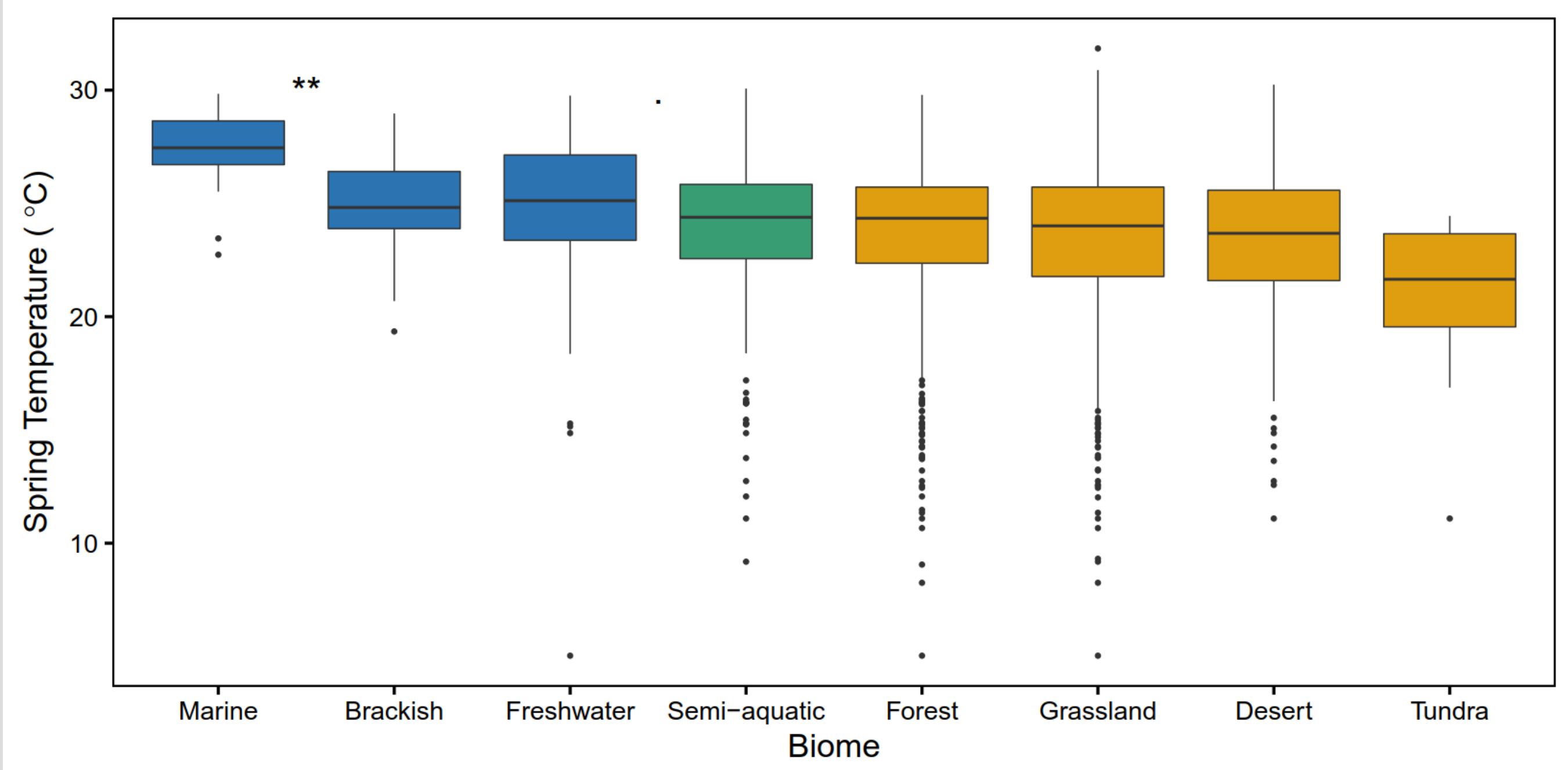




\section{WHICH ADAPTATIONS/CONDITIONS
PRECEDED THE MARINE INVASIONS? \\ WHICH ADAPTATIONS/CONDITIONS
PRECEDED THE MARINE INVASIONS? (PERHAPS ENABLING THEM)}




\section{FIRST, RECONSTRUCT WHEN THE MARINE INVASIONS OCCURRED}

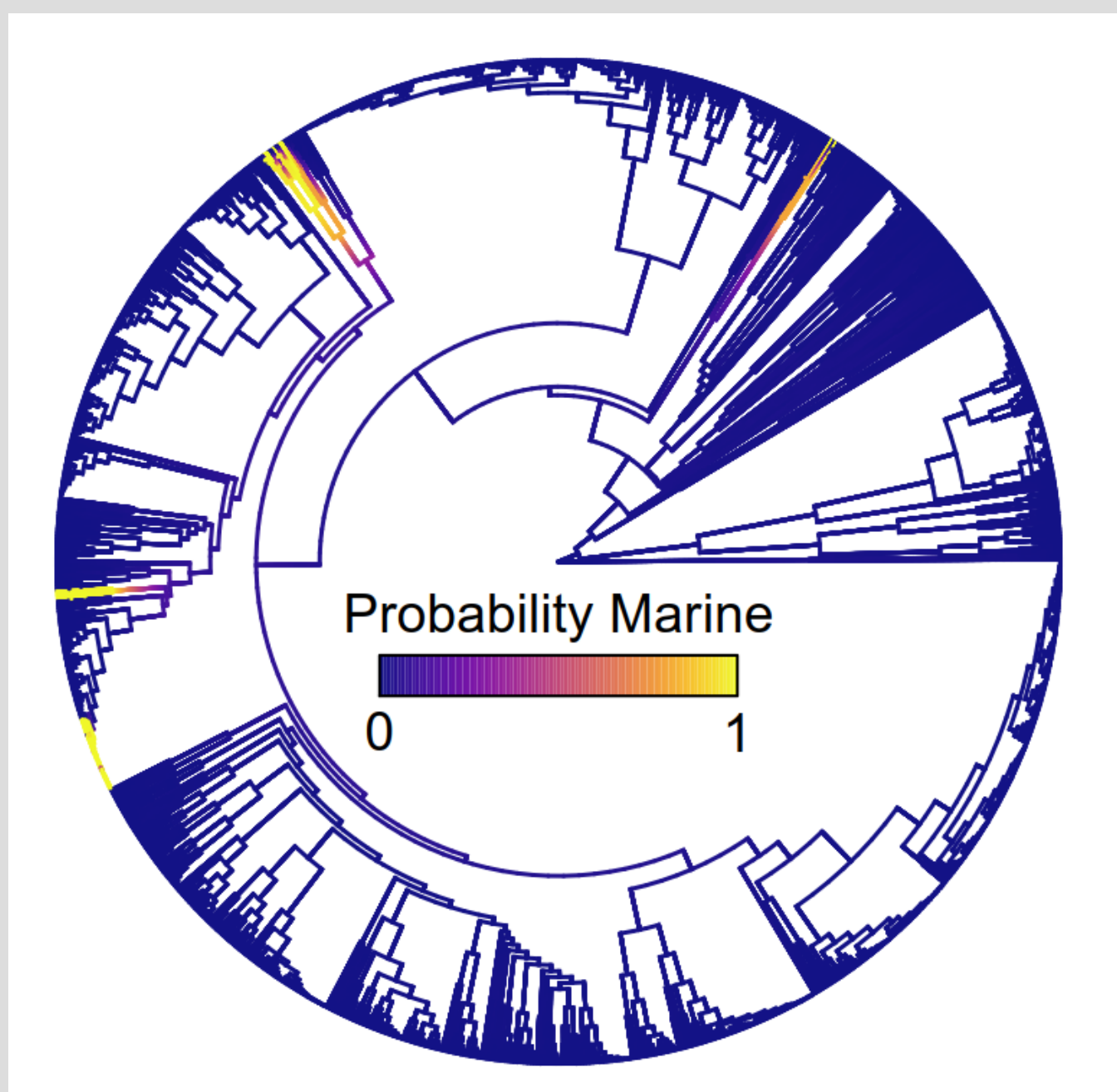




\section{THEN, RECONSTRUCT OTHER TRAITS AND ENVIRONMENTAL VARIABLES}
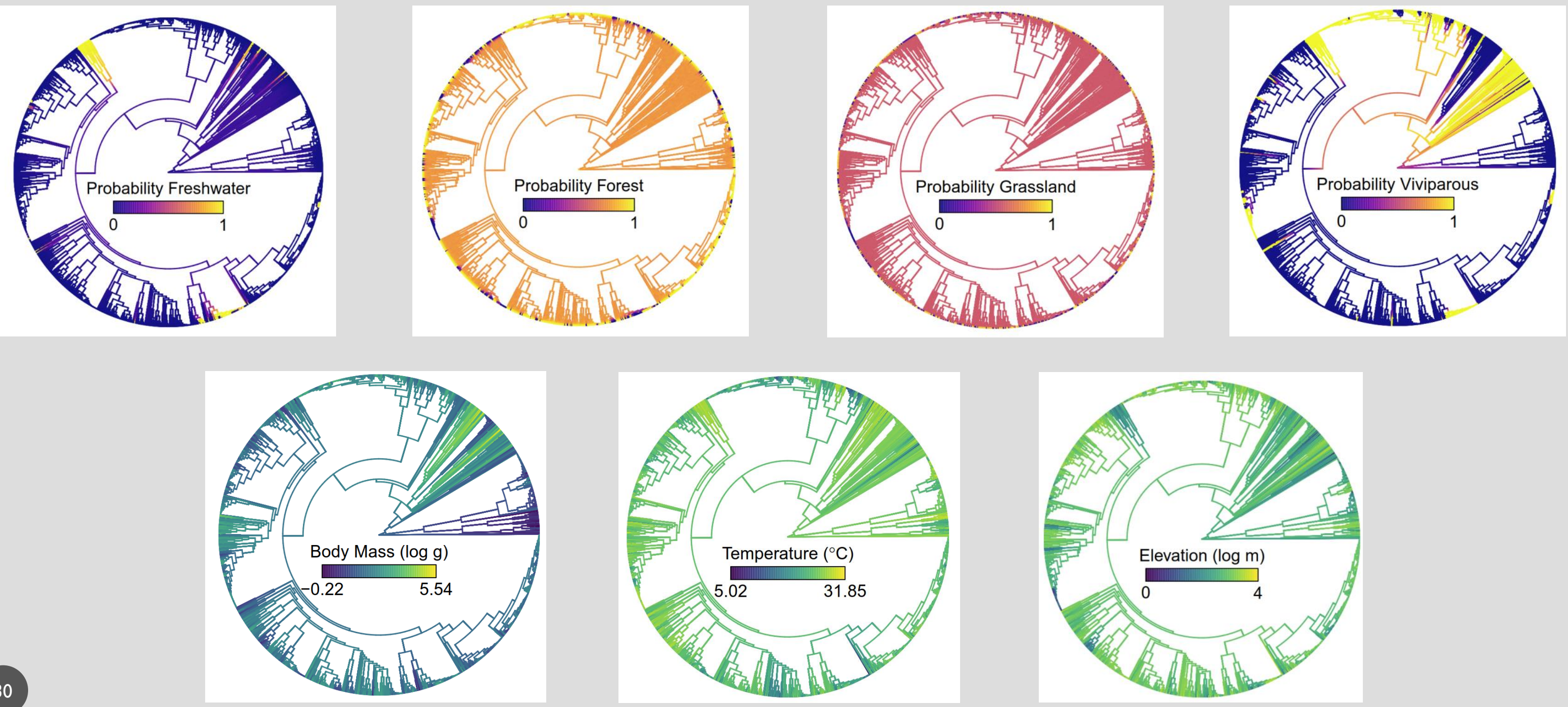


\section{JOINT RECONSTRUCTIONS}

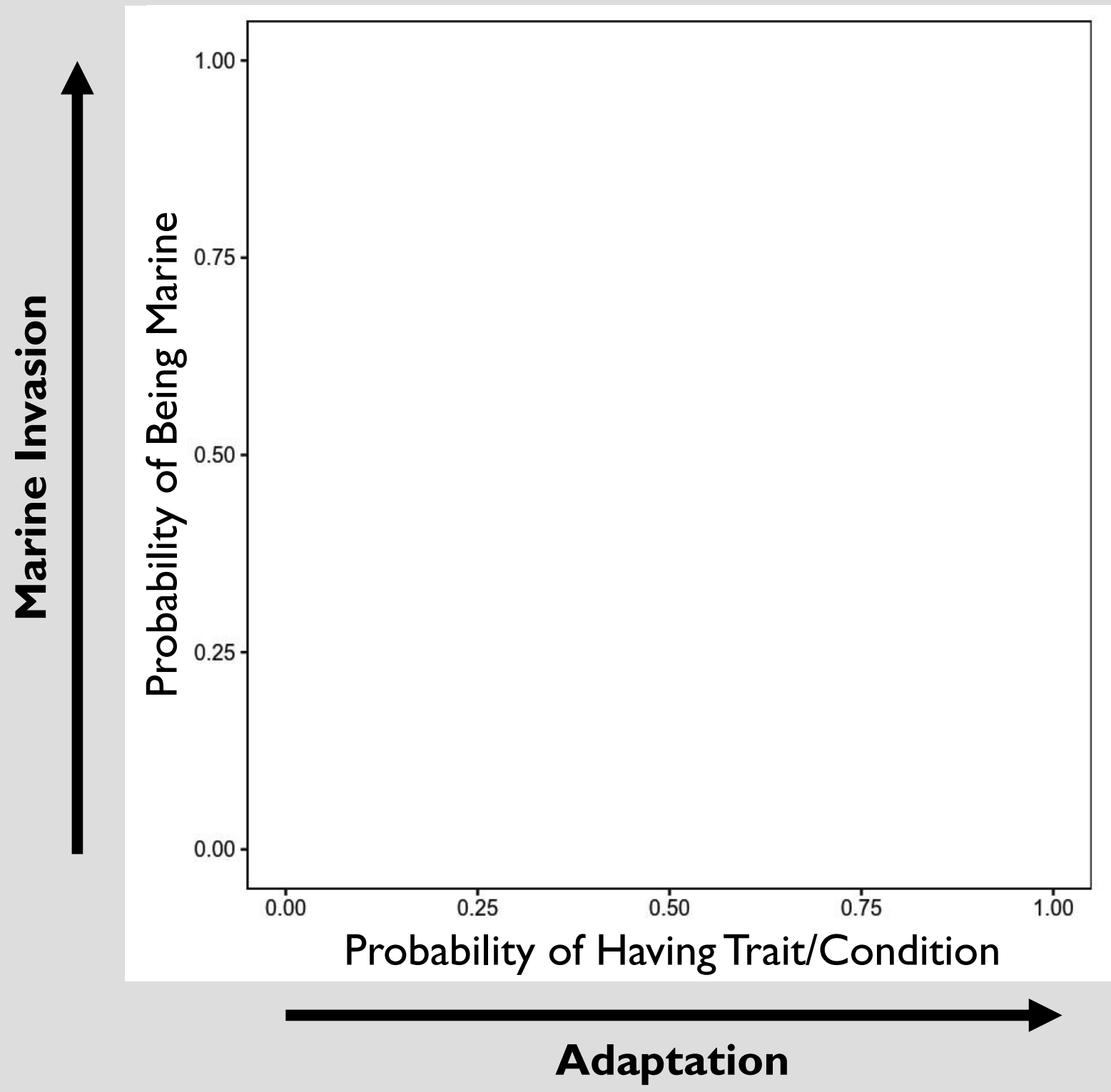




\section{JOINT RECONSTRUCTIONS}

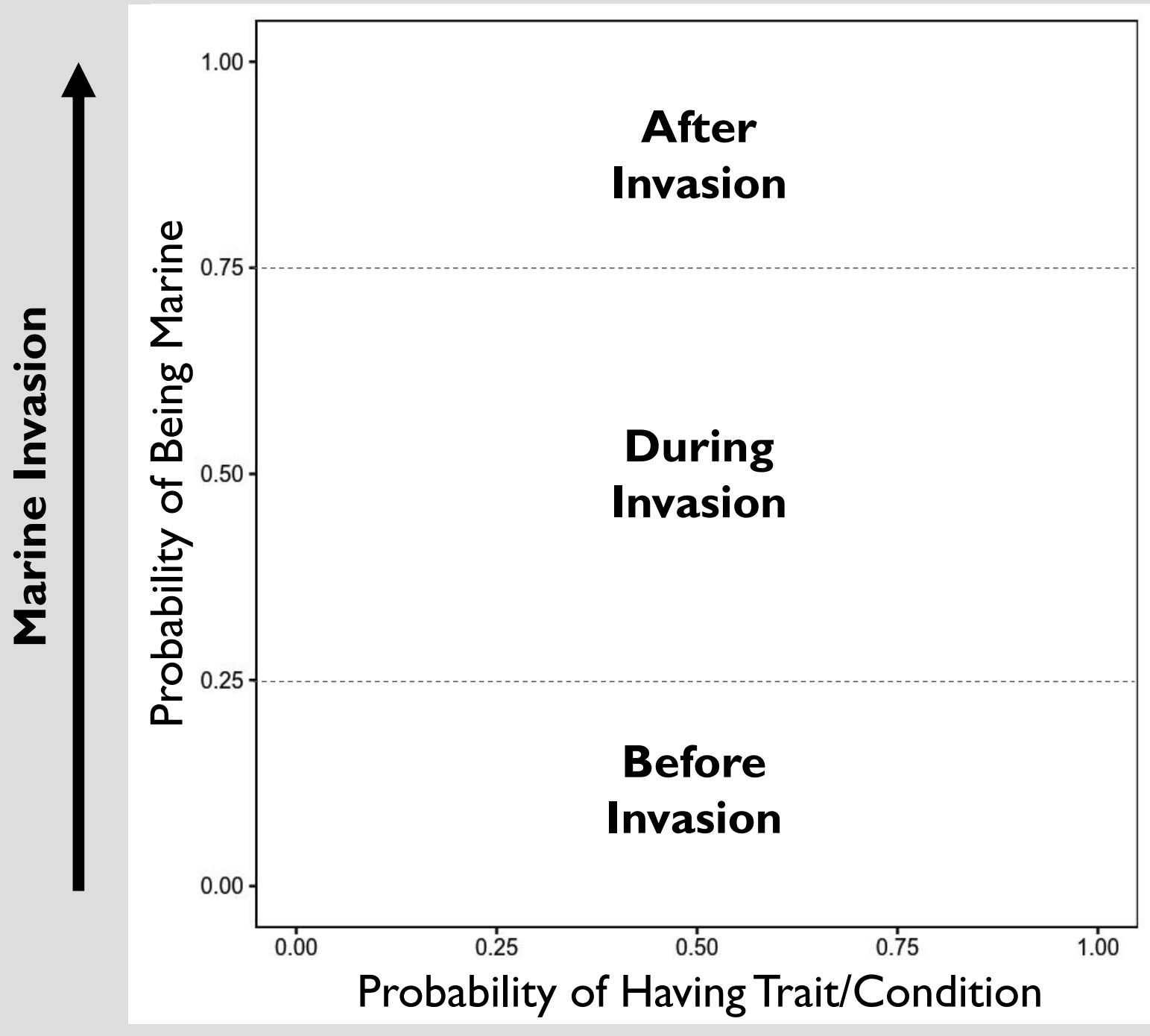

Adaptation 


\section{JOINT RECONSTRUCTIONS}

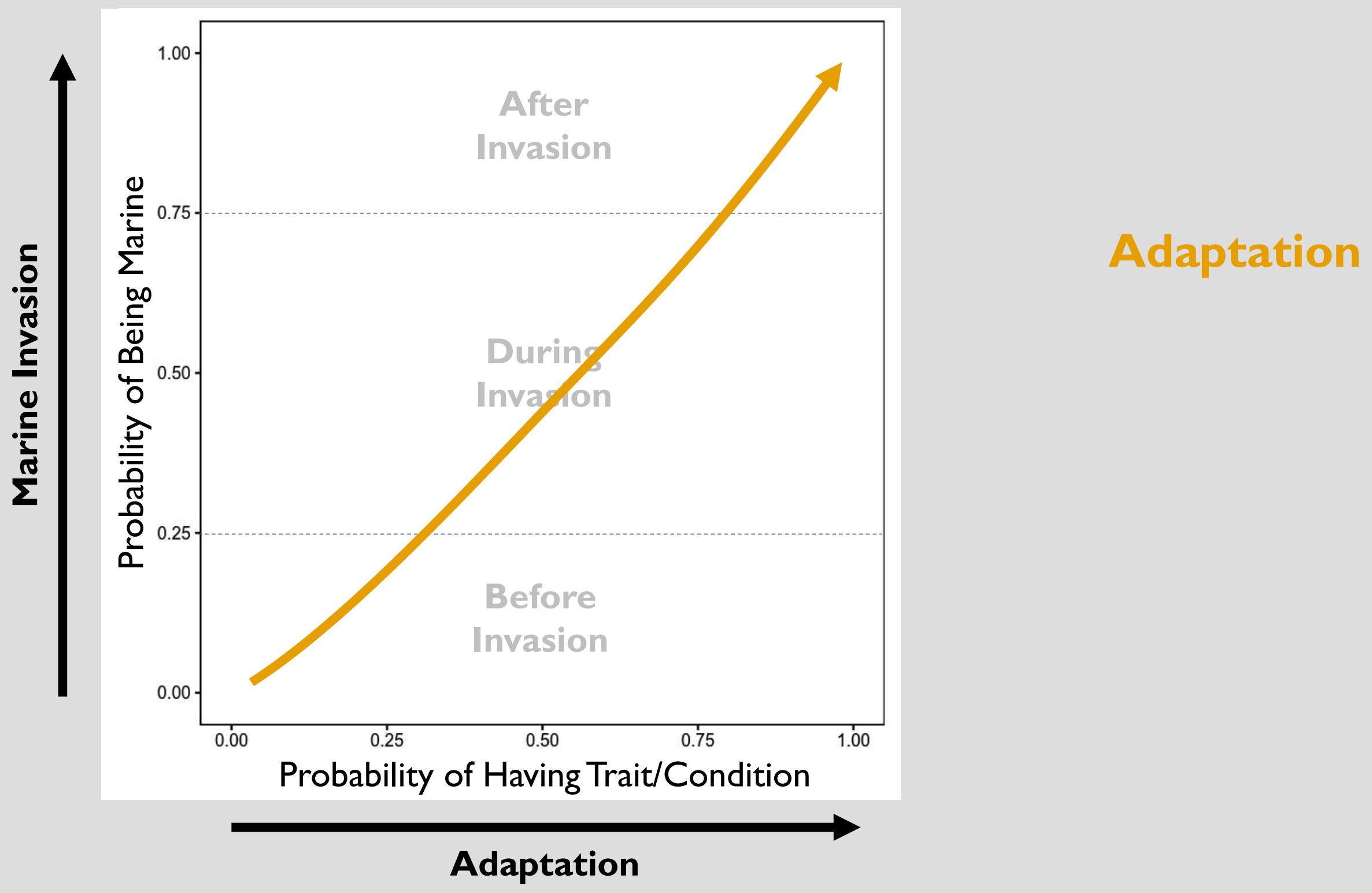




\section{JOINT RECONSTRUCTIONS}

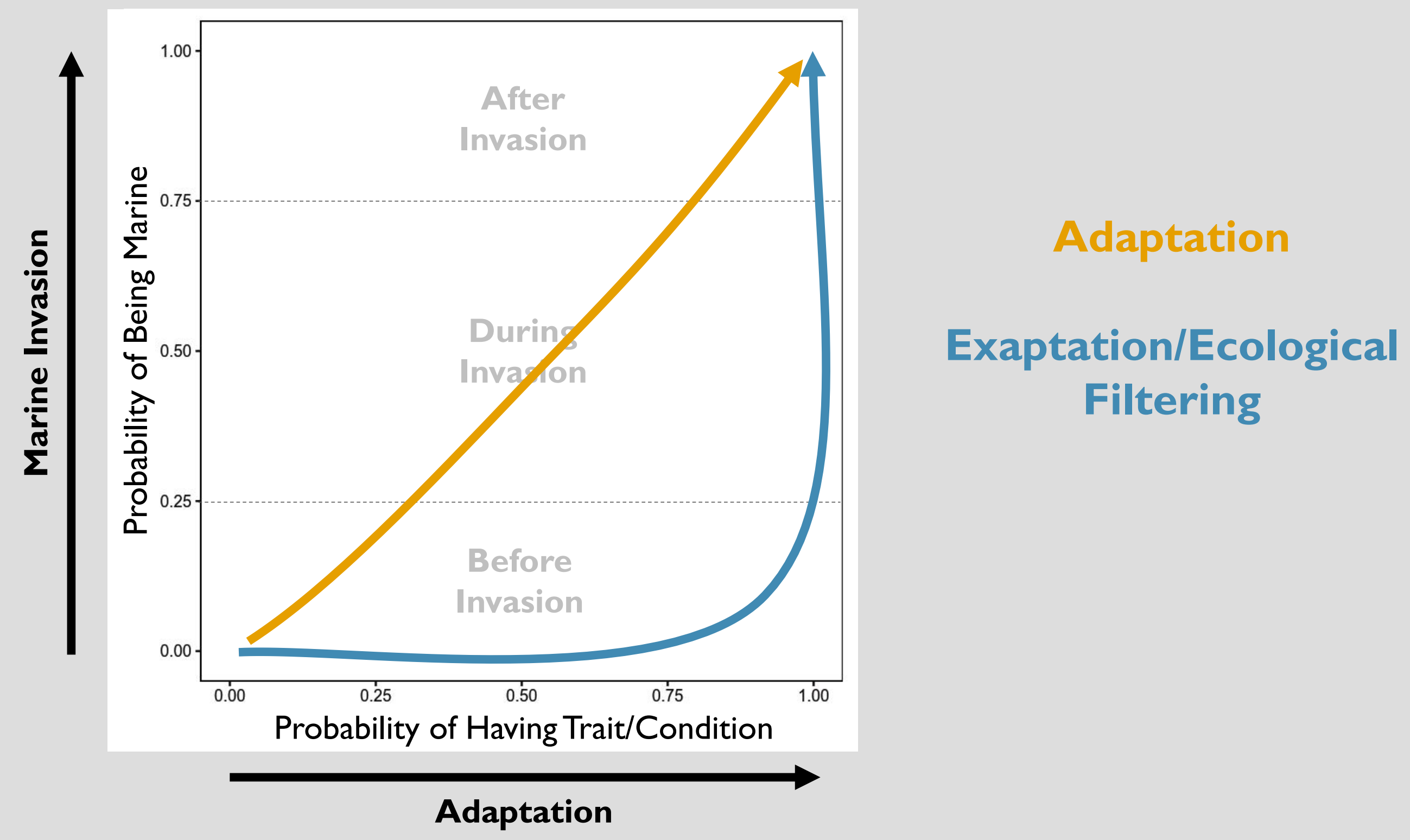




\section{JOINT RECONSTRUCTIONS}

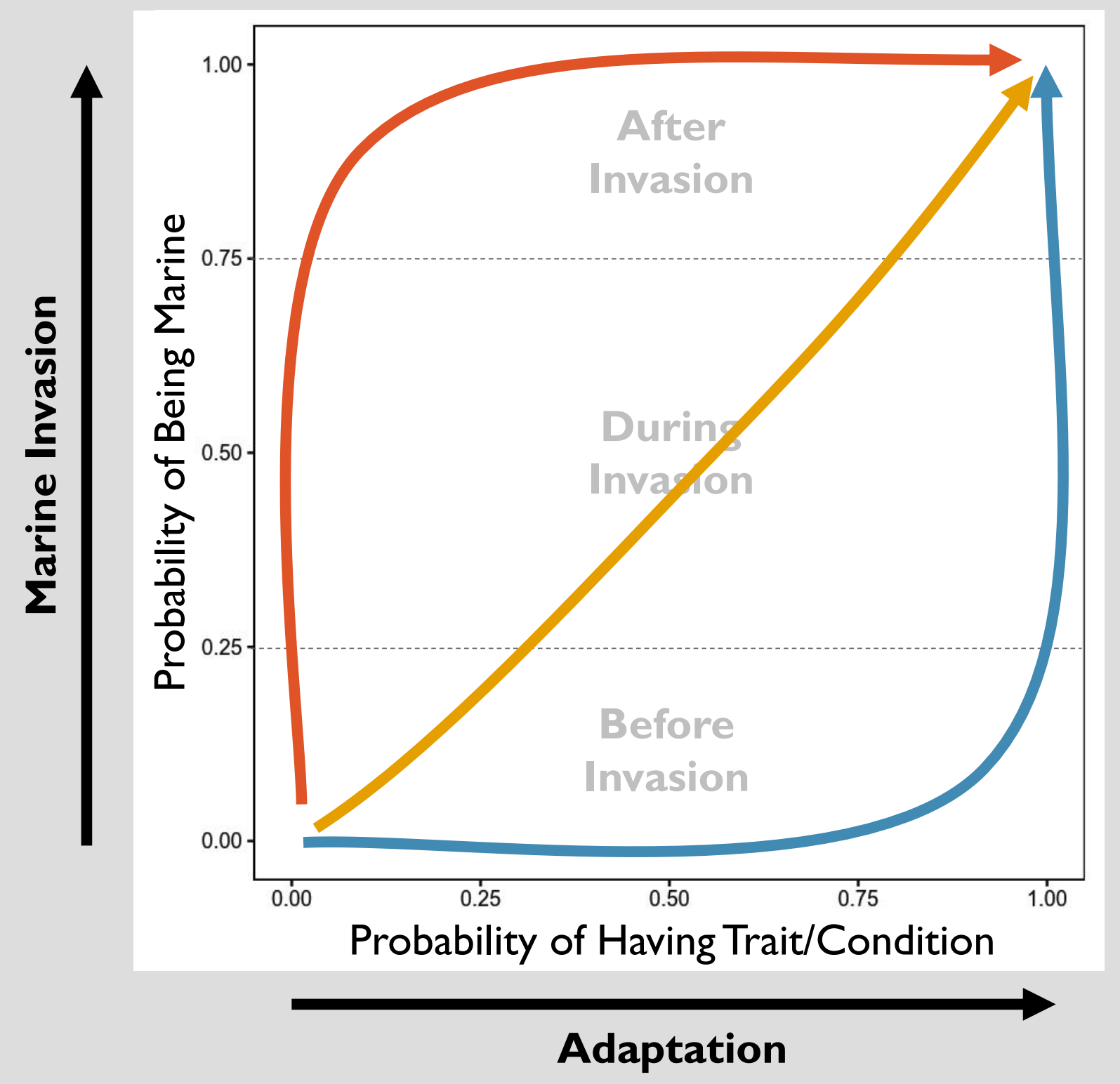

\section{Exaptation/Ecological}

Filtering

Nonaptation

(or adaptation for something else) 


\section{TESTING THE METHOD: ELEVATION}

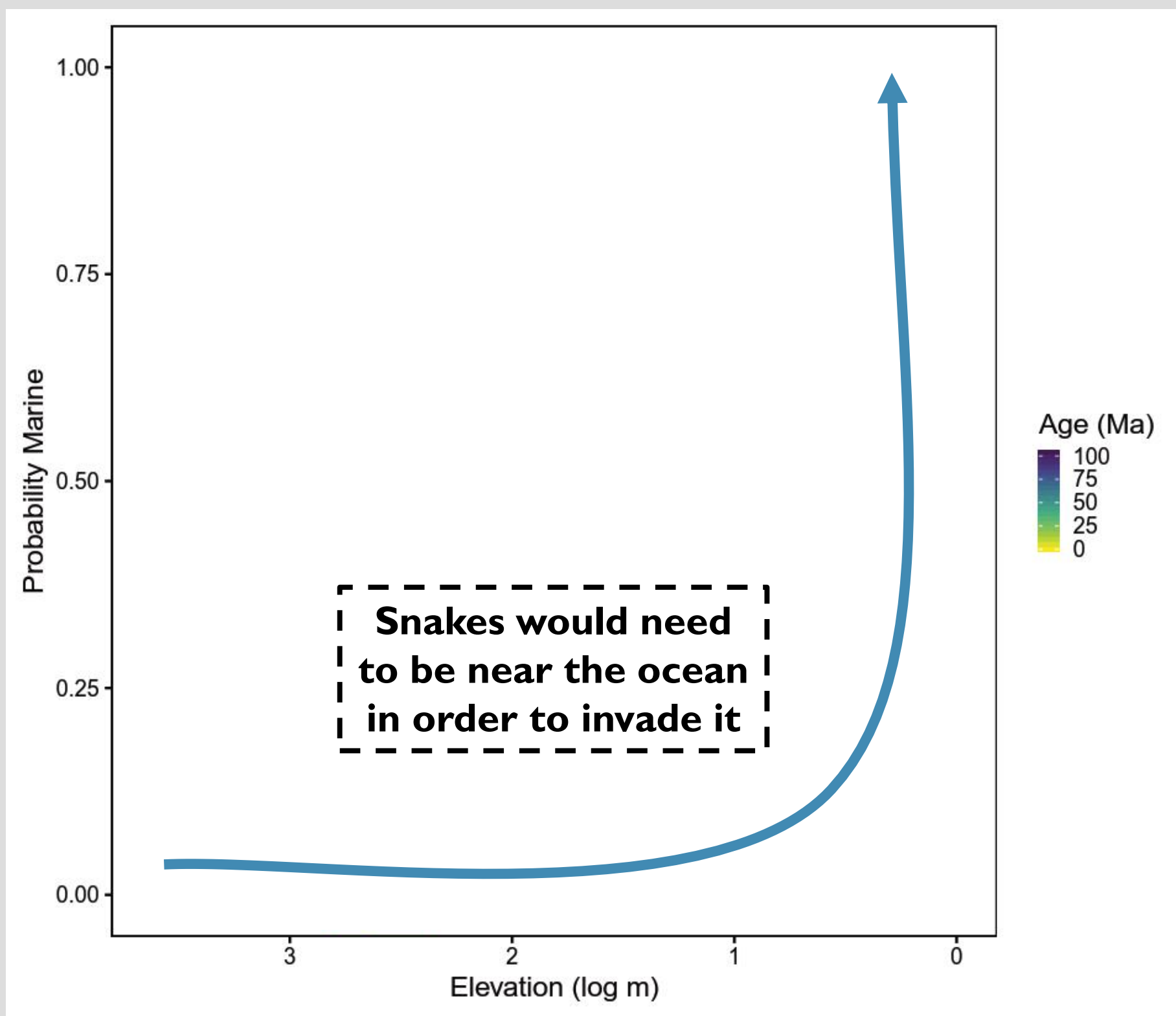




\section{TESTING THE METHOD: ELEVATION}

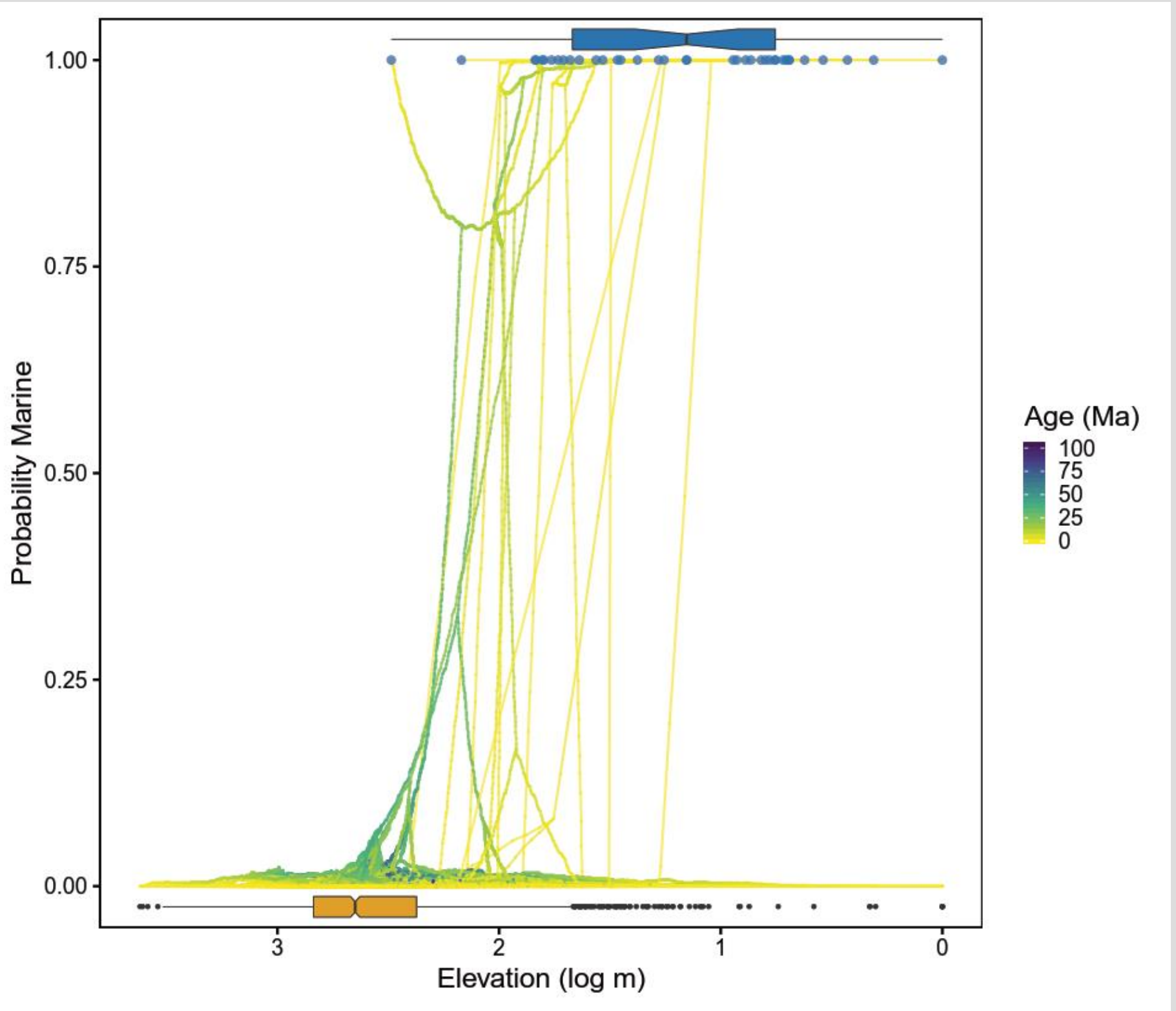




\section{TESTING THE METHOD: ELEVATION}

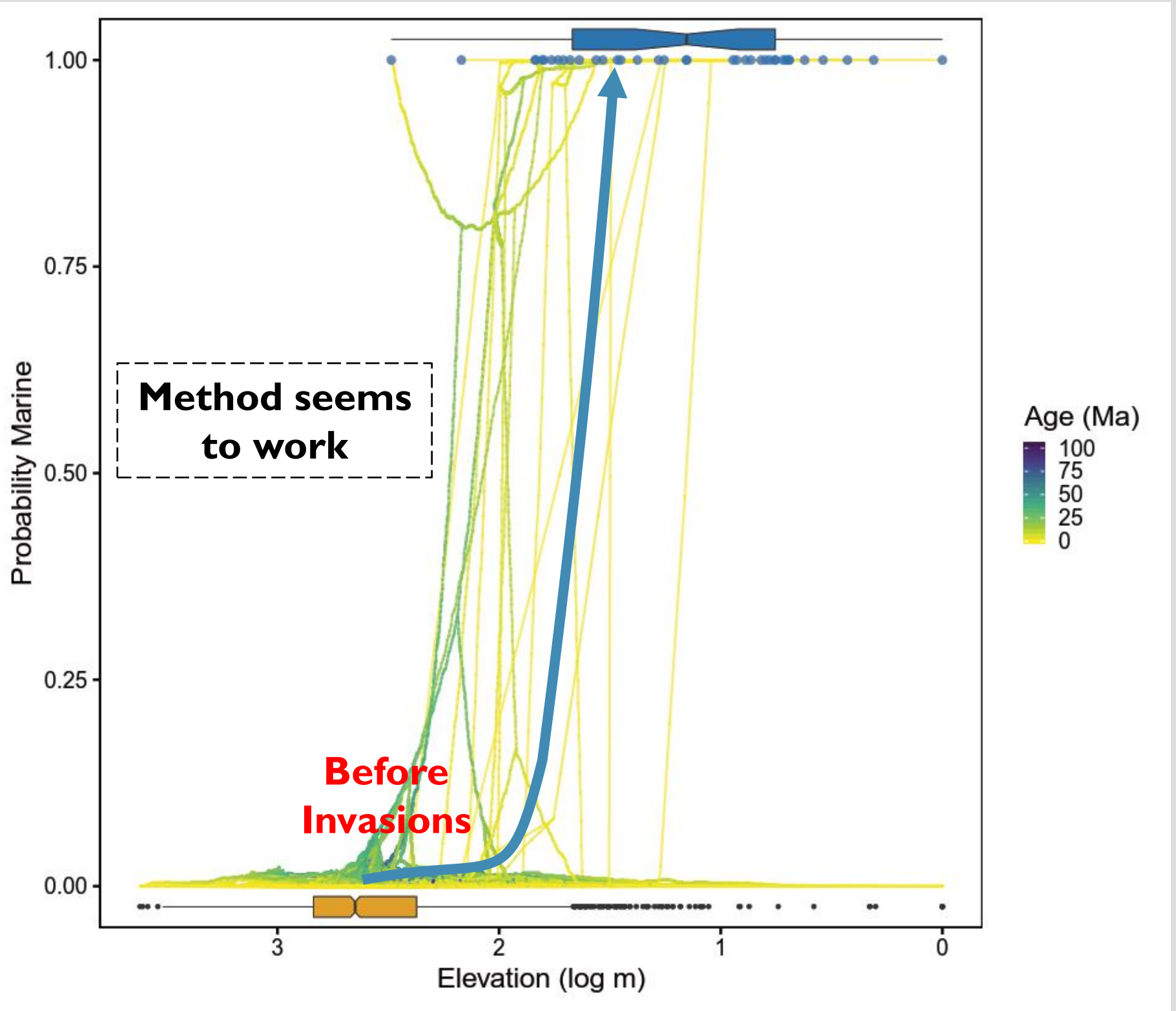




\section{TEMPERATURE}

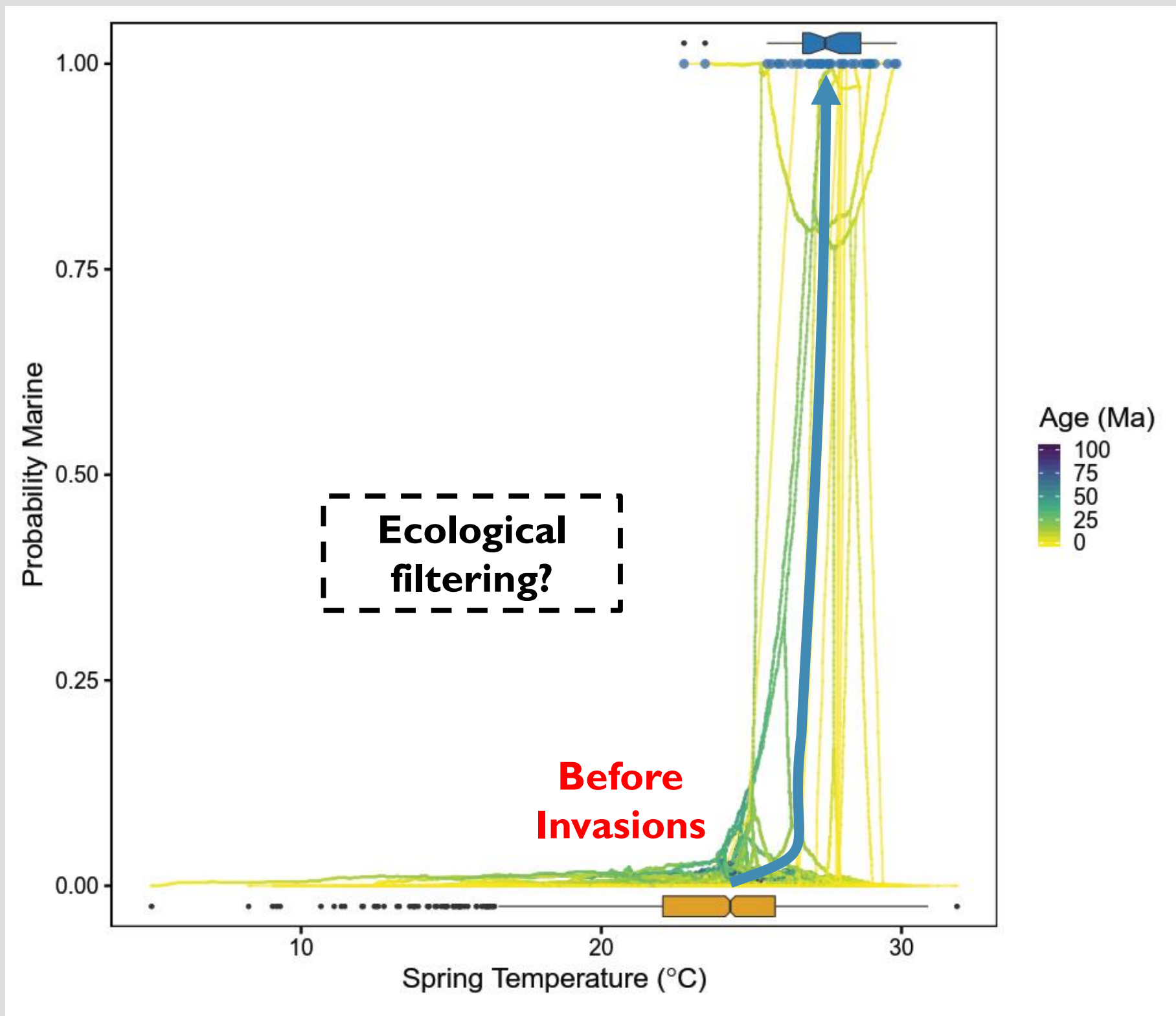




\section{BODY MASS}

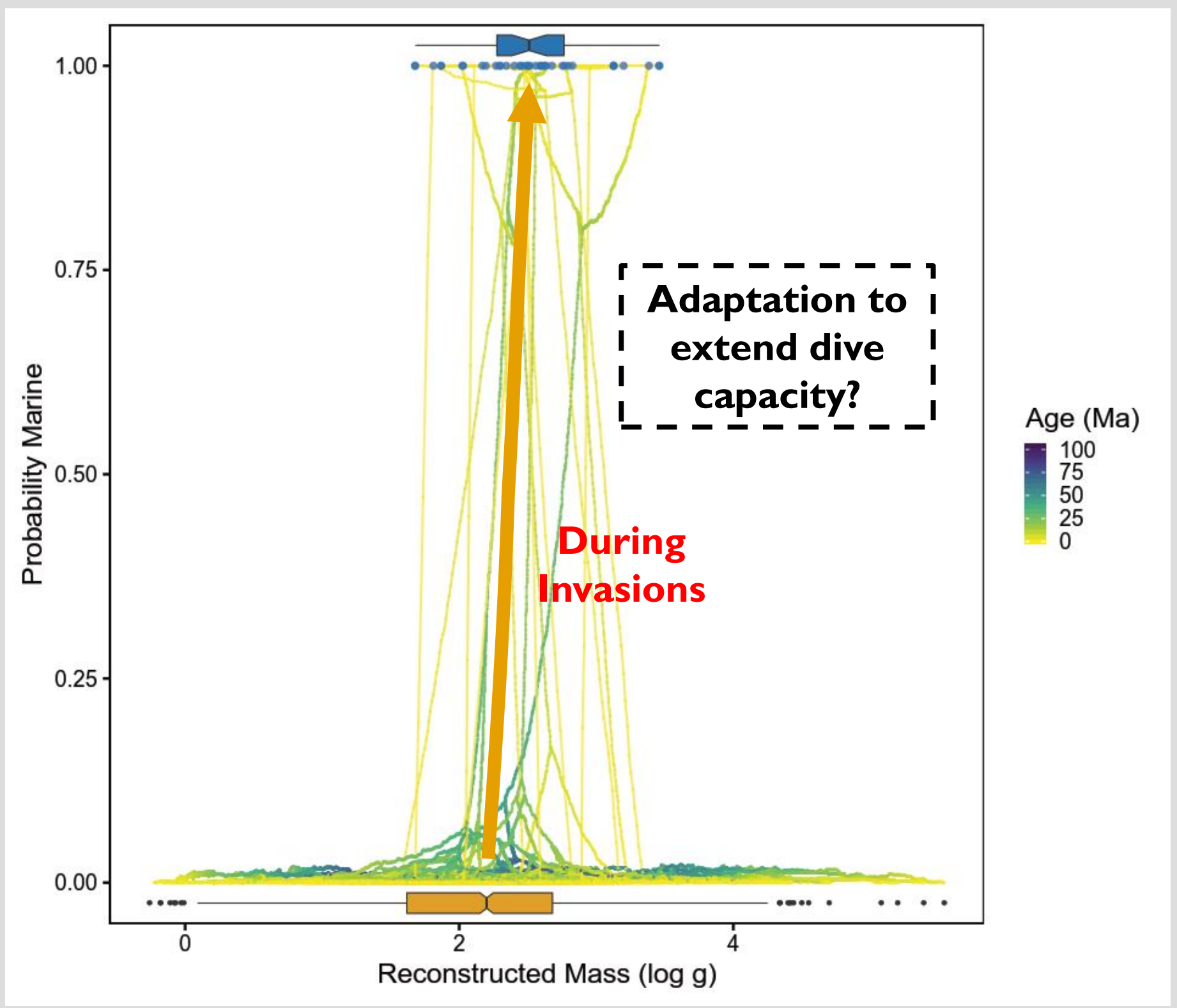




\section{FRESHWATER OCCUPANCY}

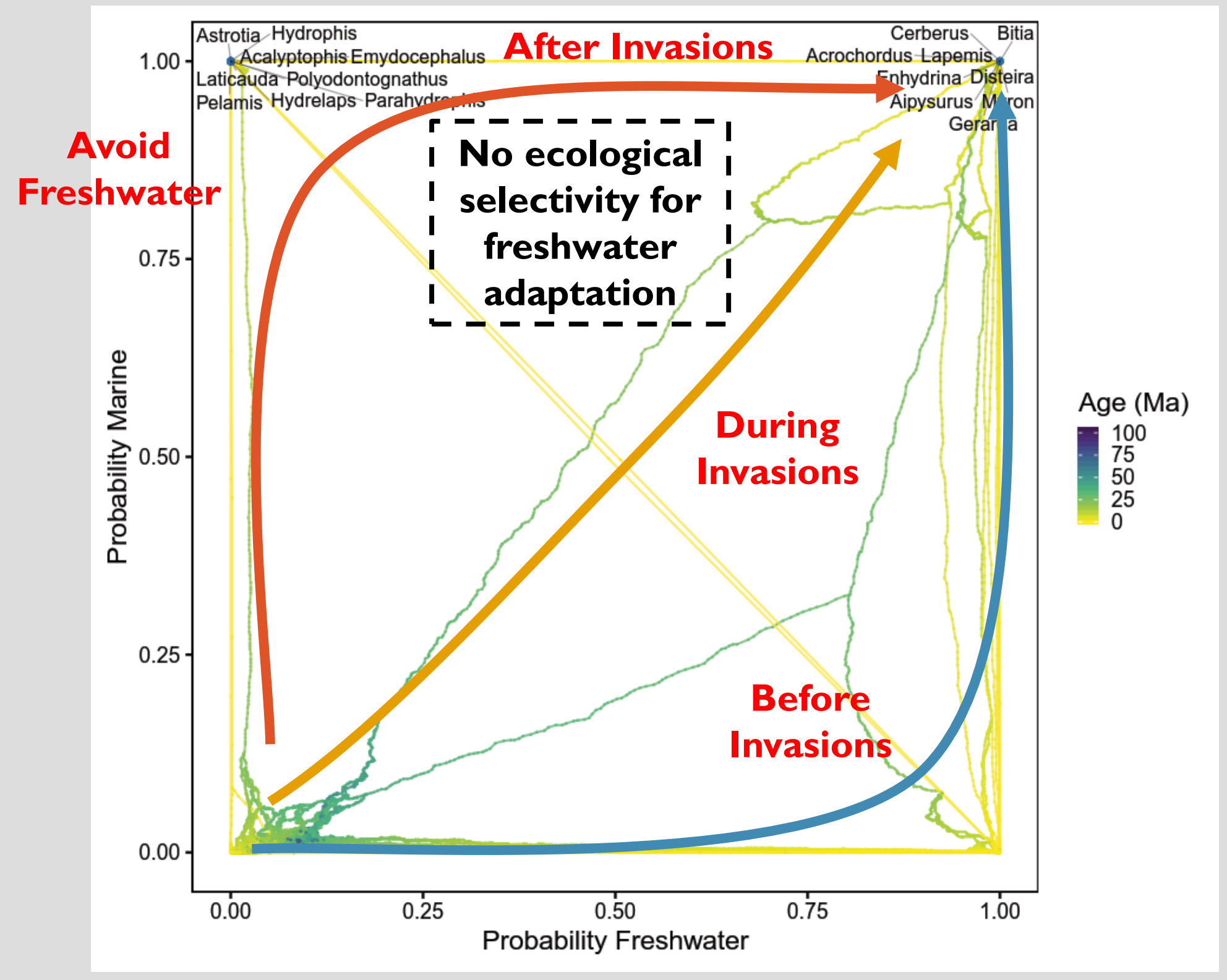




\section{VIVIPARITY}

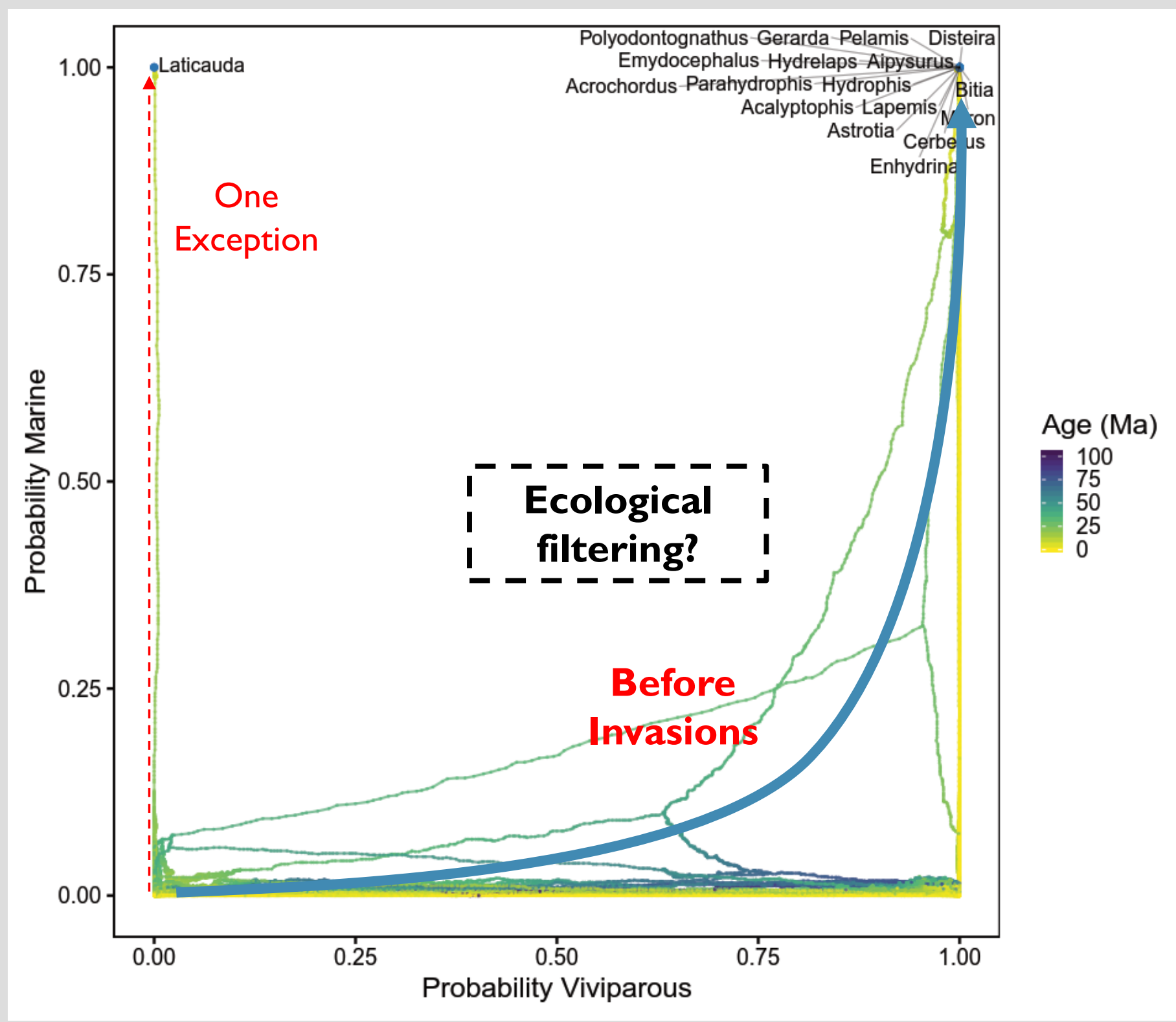




\section{CONCLUSIONS}

- While aquatic snakes are significantly larger than their terrestrial counterparts, it doesn't match the extent in mammals or crocs

Viviparity appears to have evolved before these lineages invaded the ocean, likely as an adaptation for some other reason

- This facilitated marine invasions of snakes from many different environments, but only if those environments were in tropical regions at low elevation 


\title{
ACKNOWLEDGMENTS
}

\author{
Elsie Carrillo \\ Christianne Orsmby \\ Jonathan Payne \\ Payne Paleobiology Lab \\ Lyons Paleoecology Lab
}




\section{TIERING}

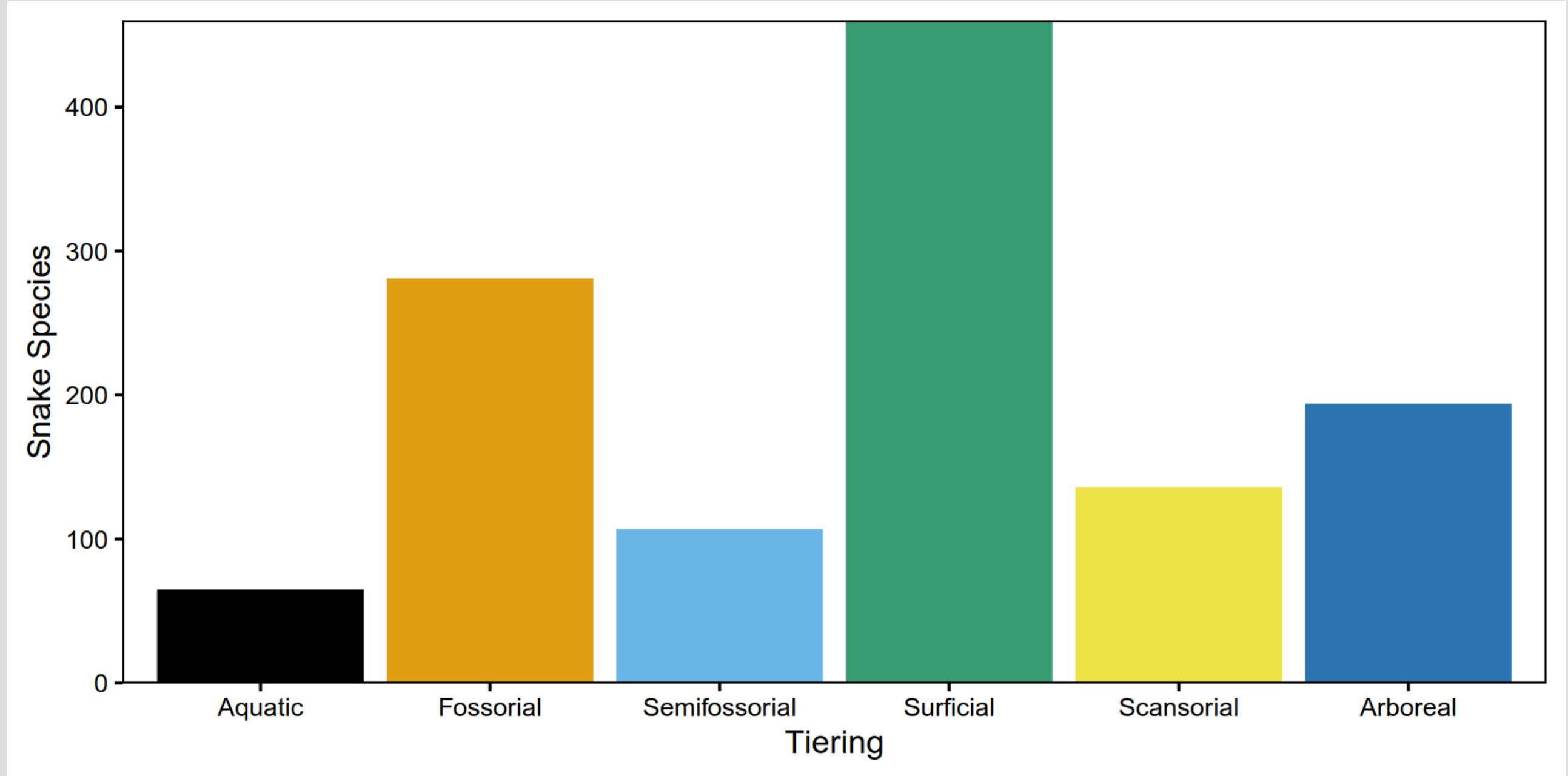




\section{REPRODUCTIVE MODE BY BIOME}

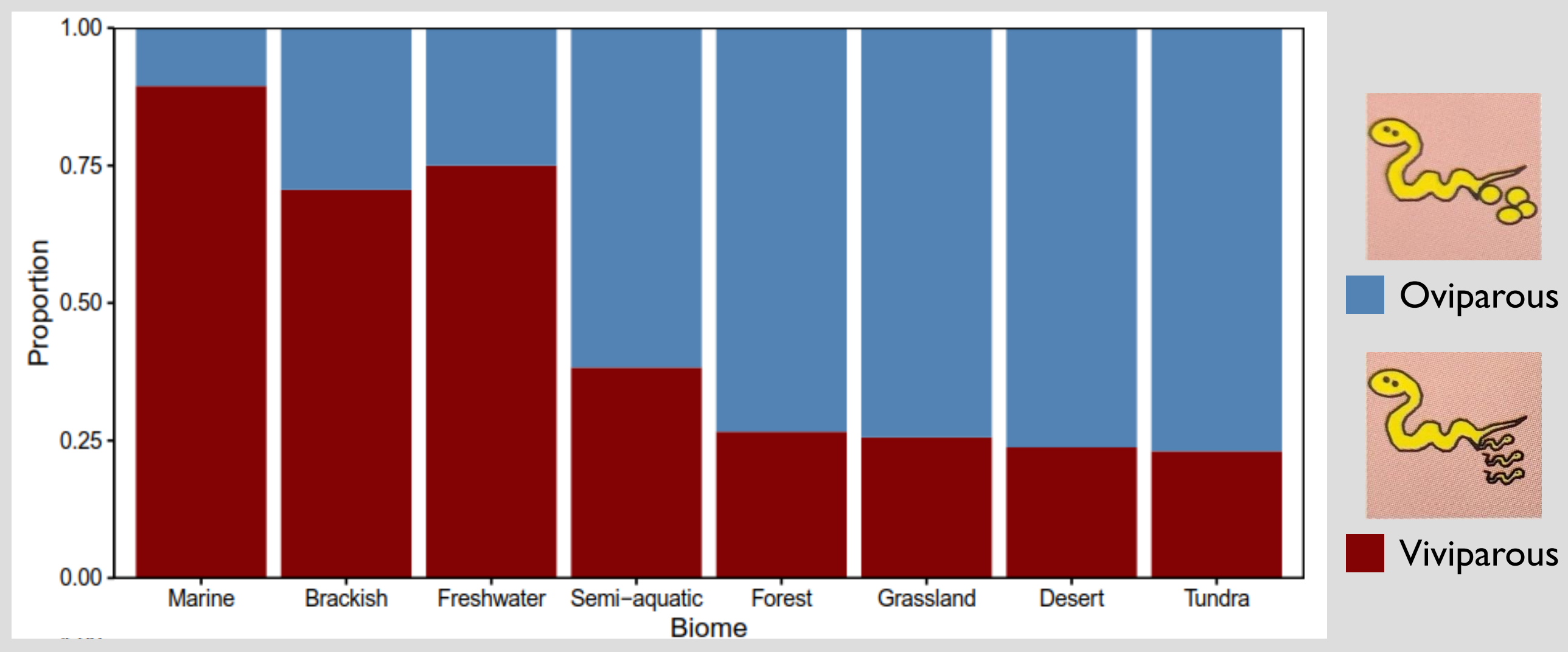




\section{ELEVATION BY BIOME}

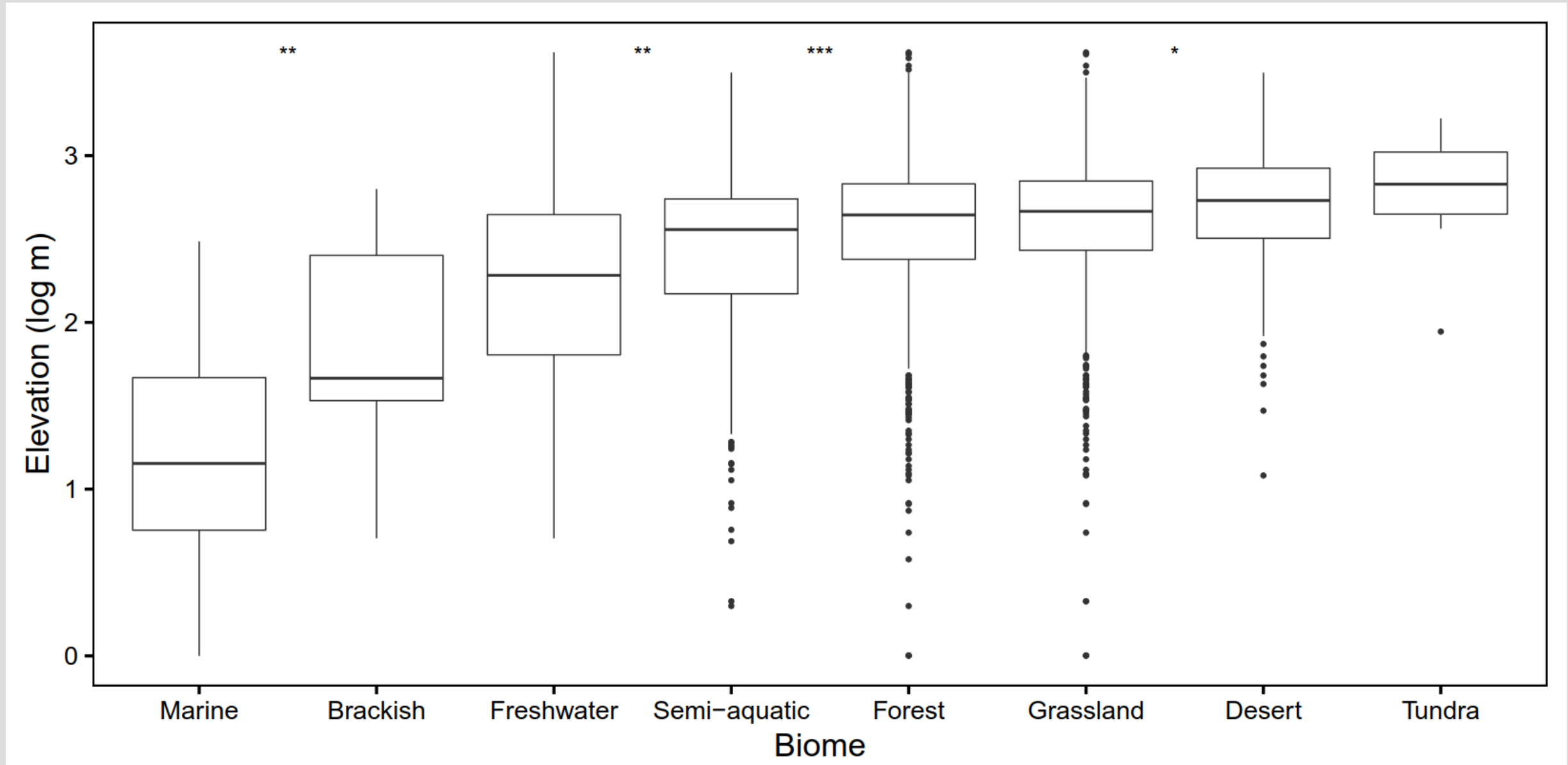


Forest Occupancy

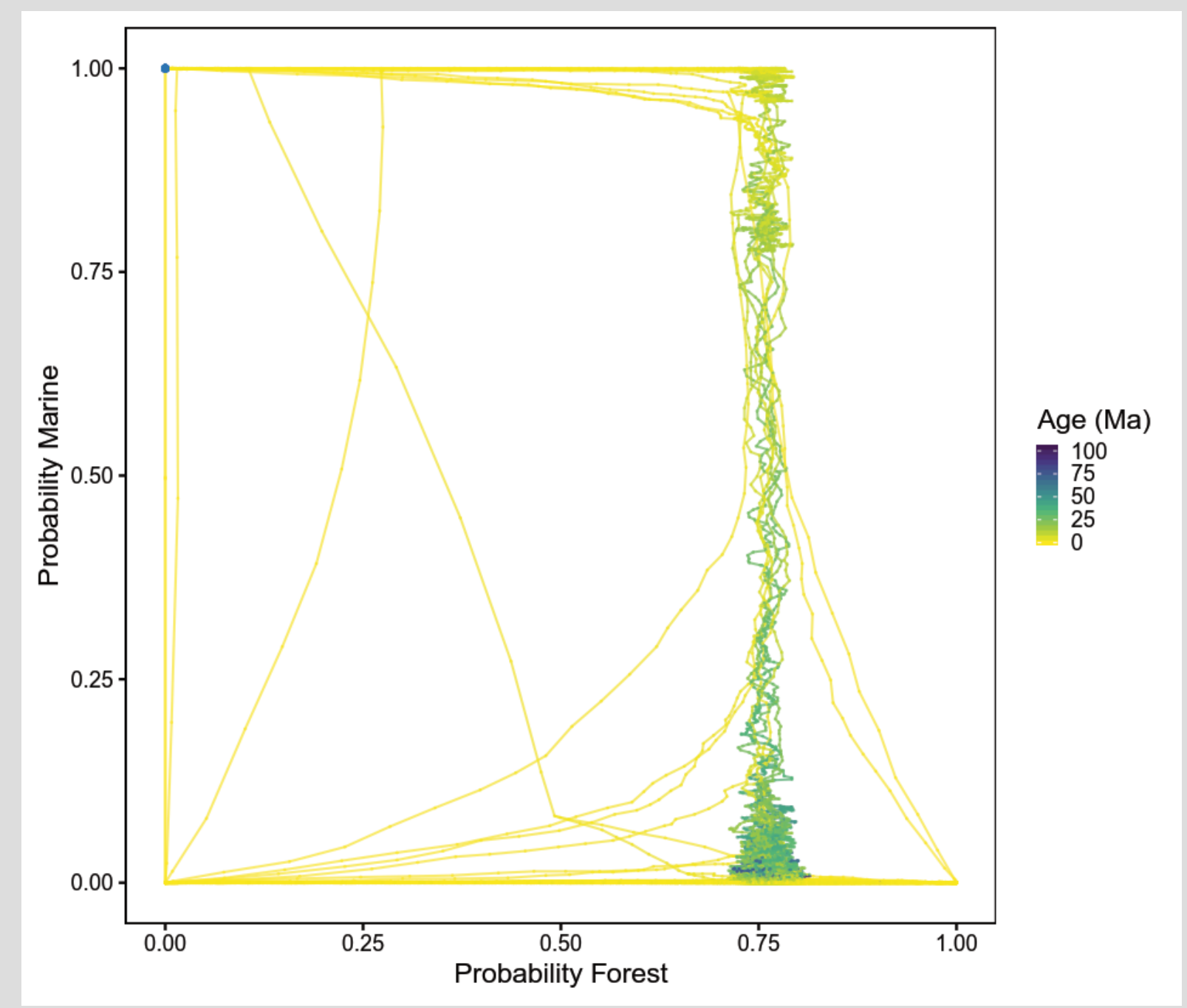

\section{Grassland Occupancy}

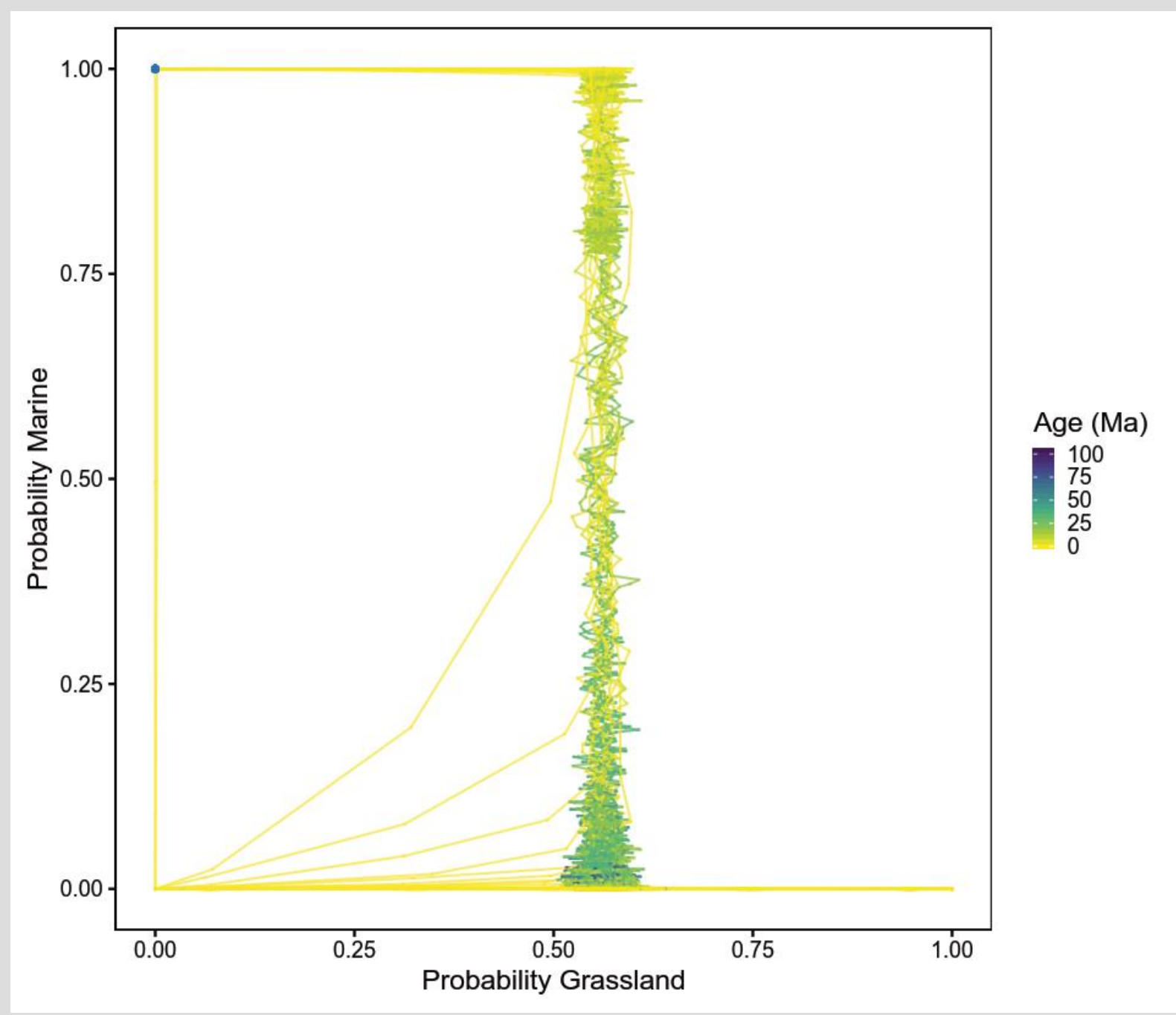


Forest Occupancy

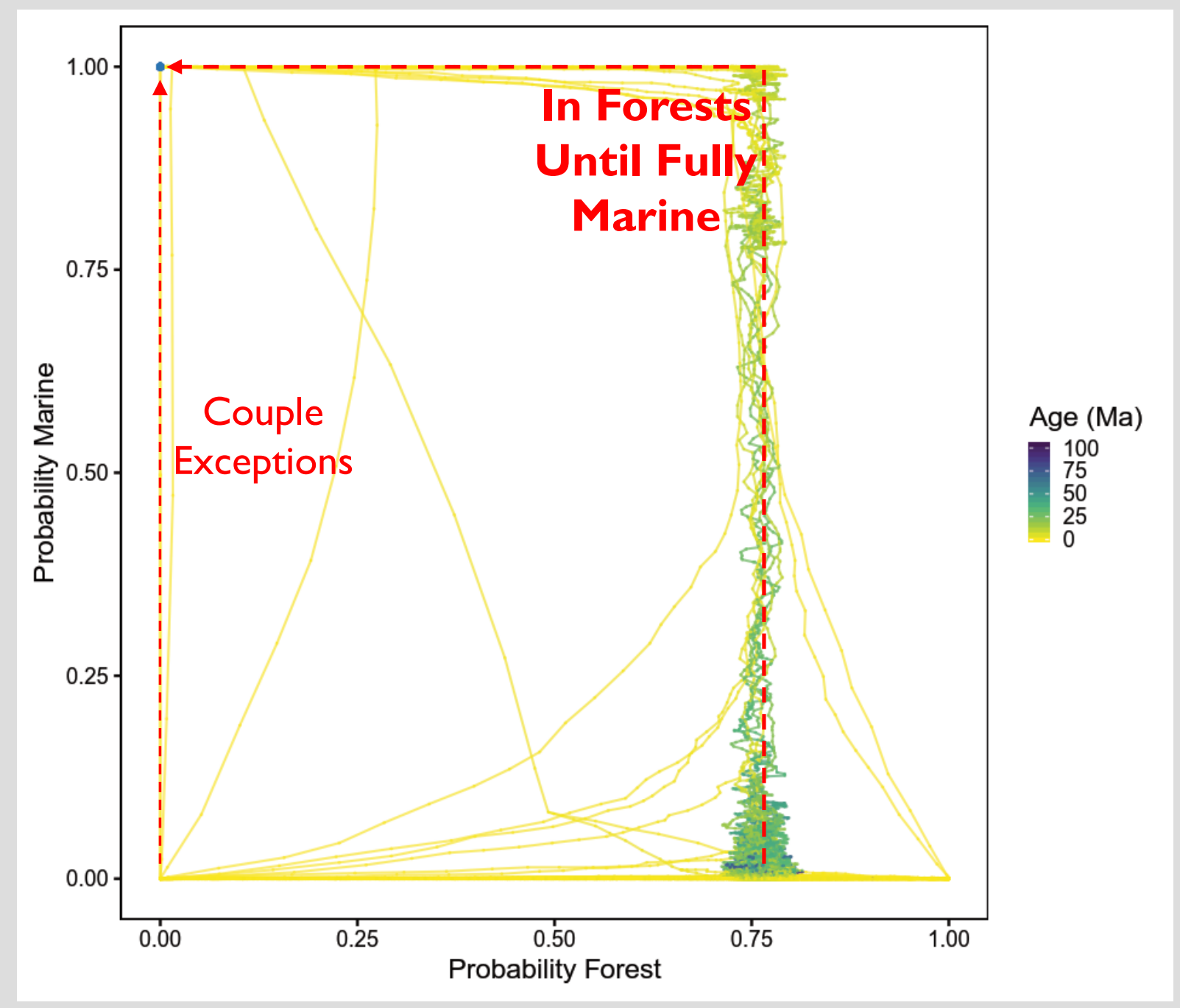

Grassland Occupancy

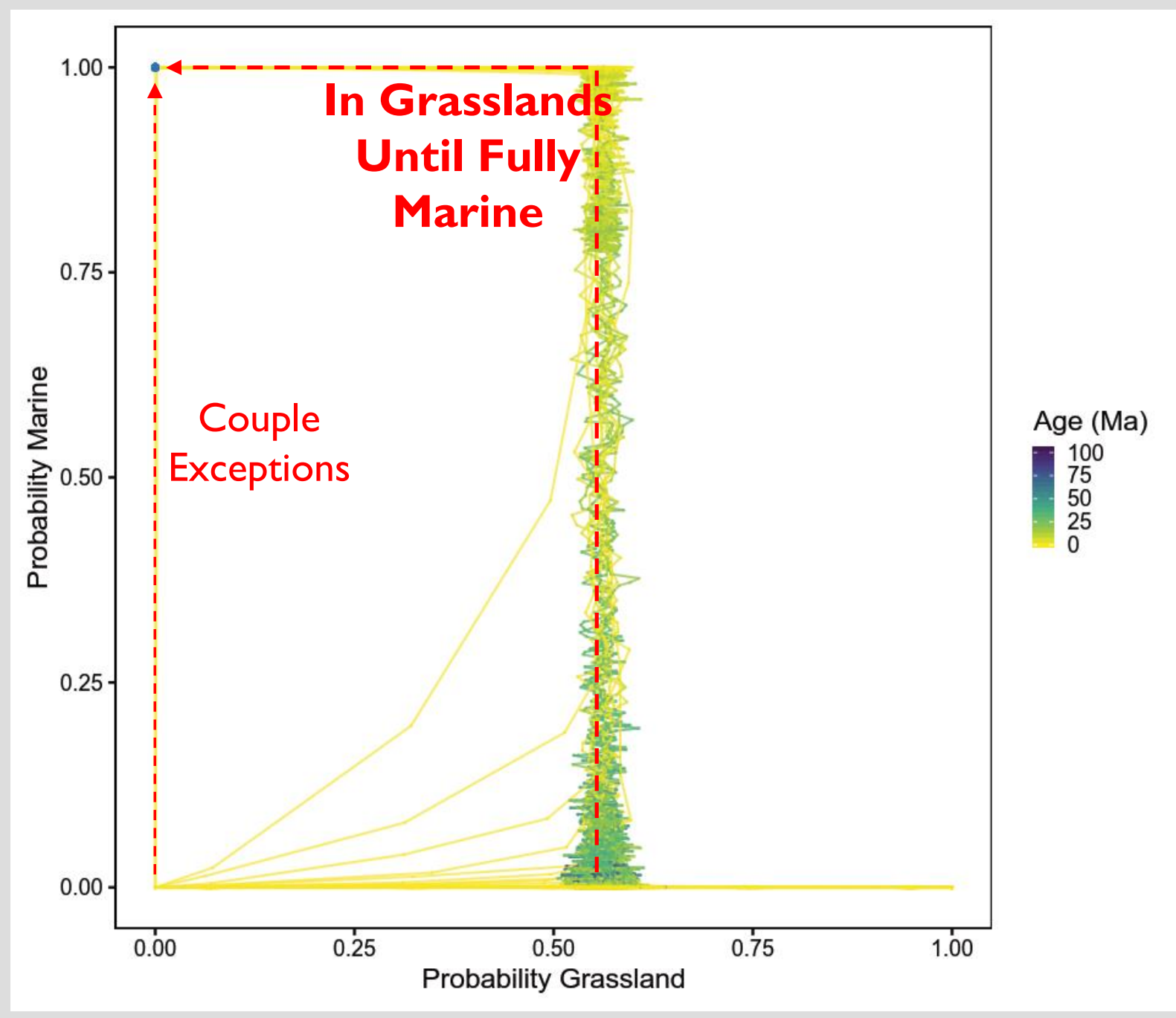




\section{Aquatic Tier}

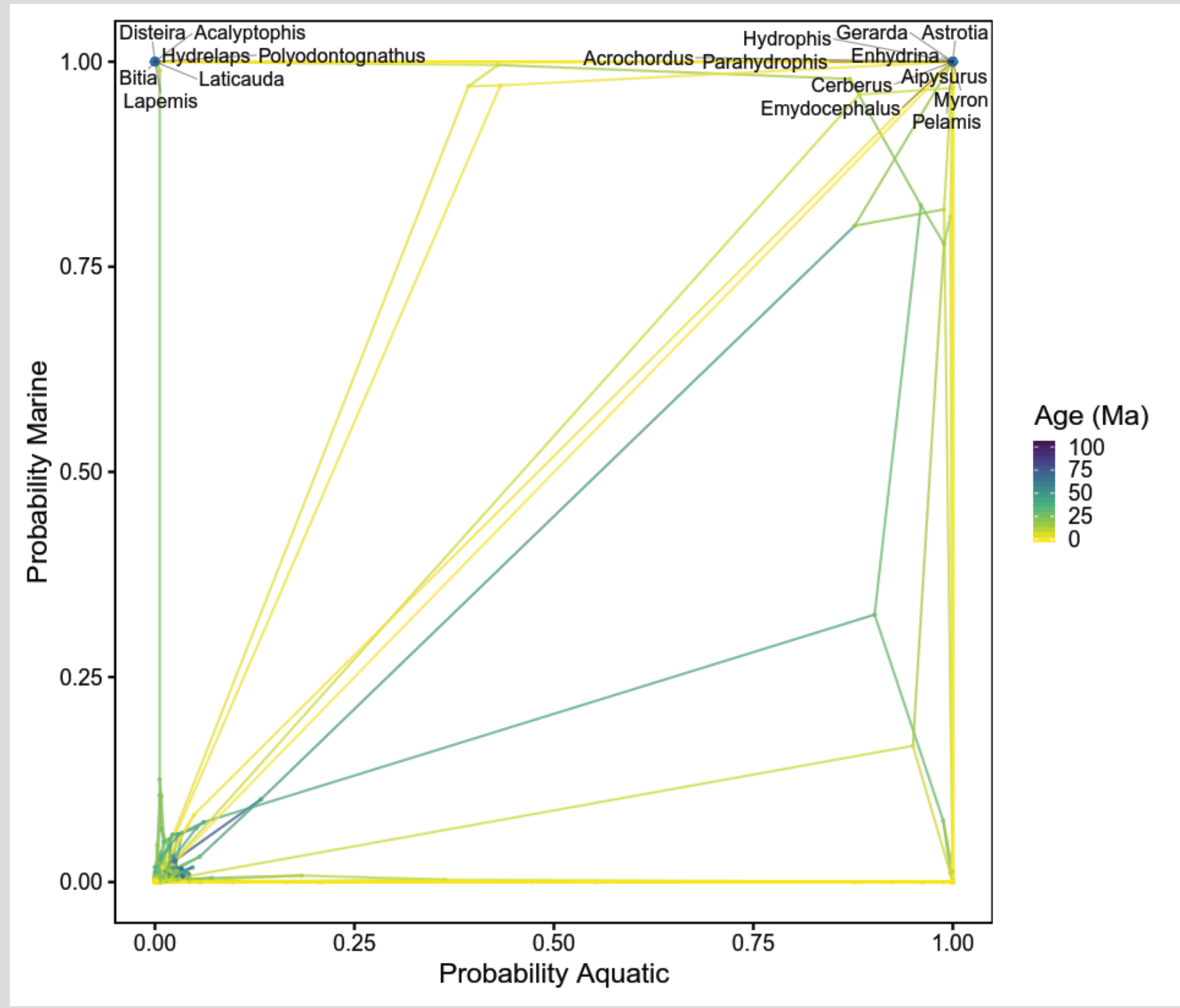




\section{Fossorial Tier}

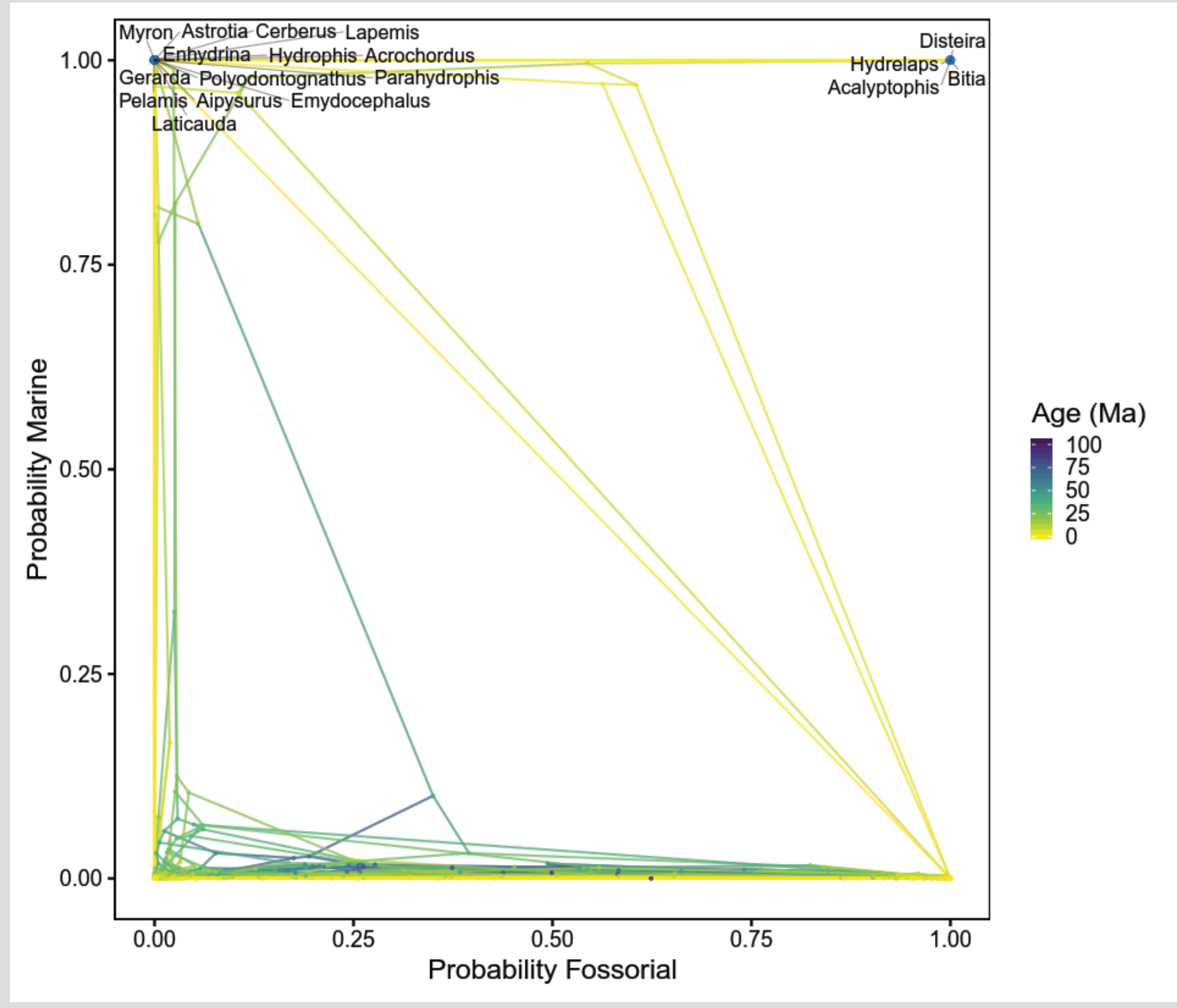




\section{Semifossorial Tier}

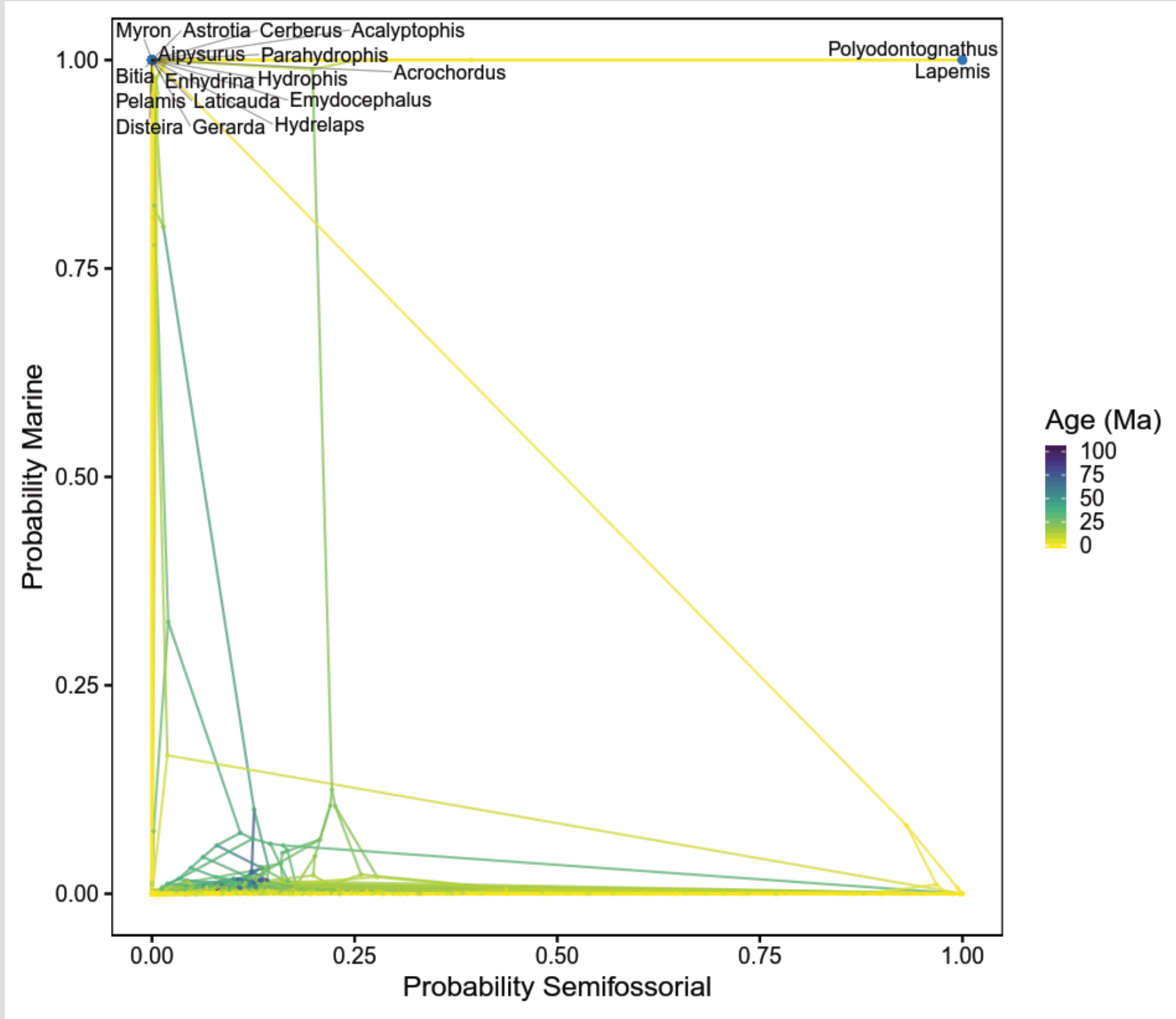




\section{Surficial Tier}

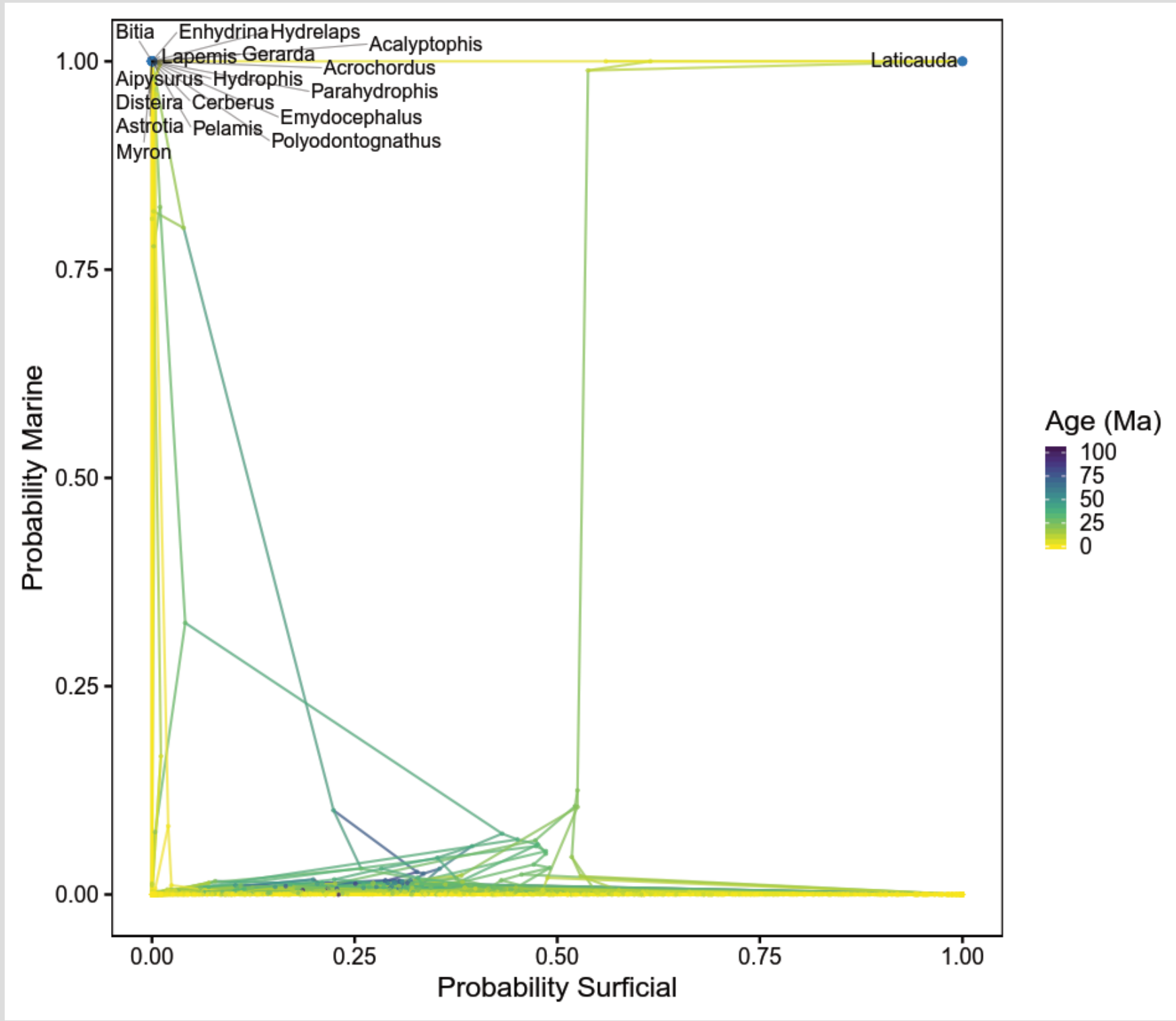




\section{Scansorial Tier}

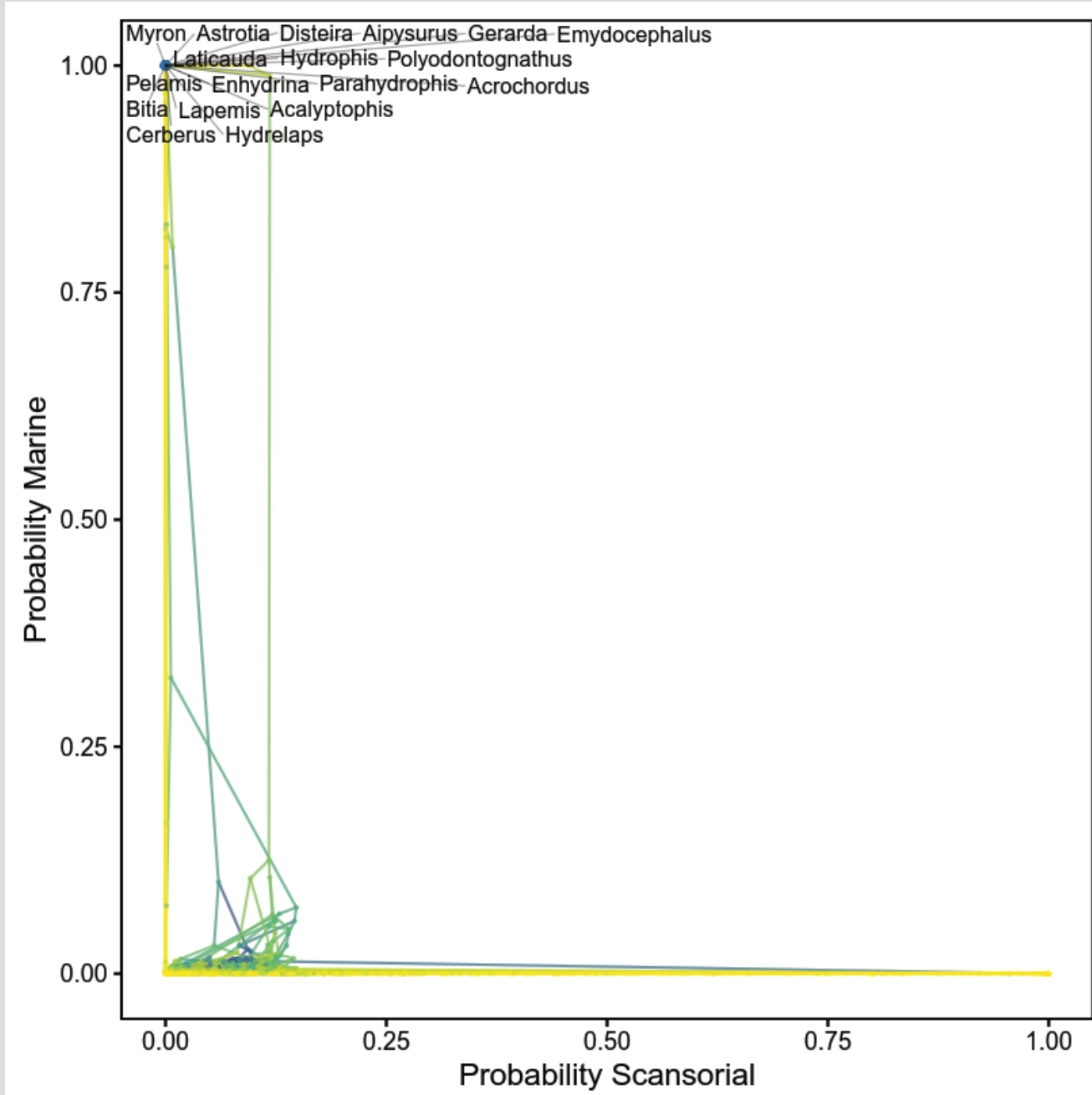

\section{Arboreal Tier}

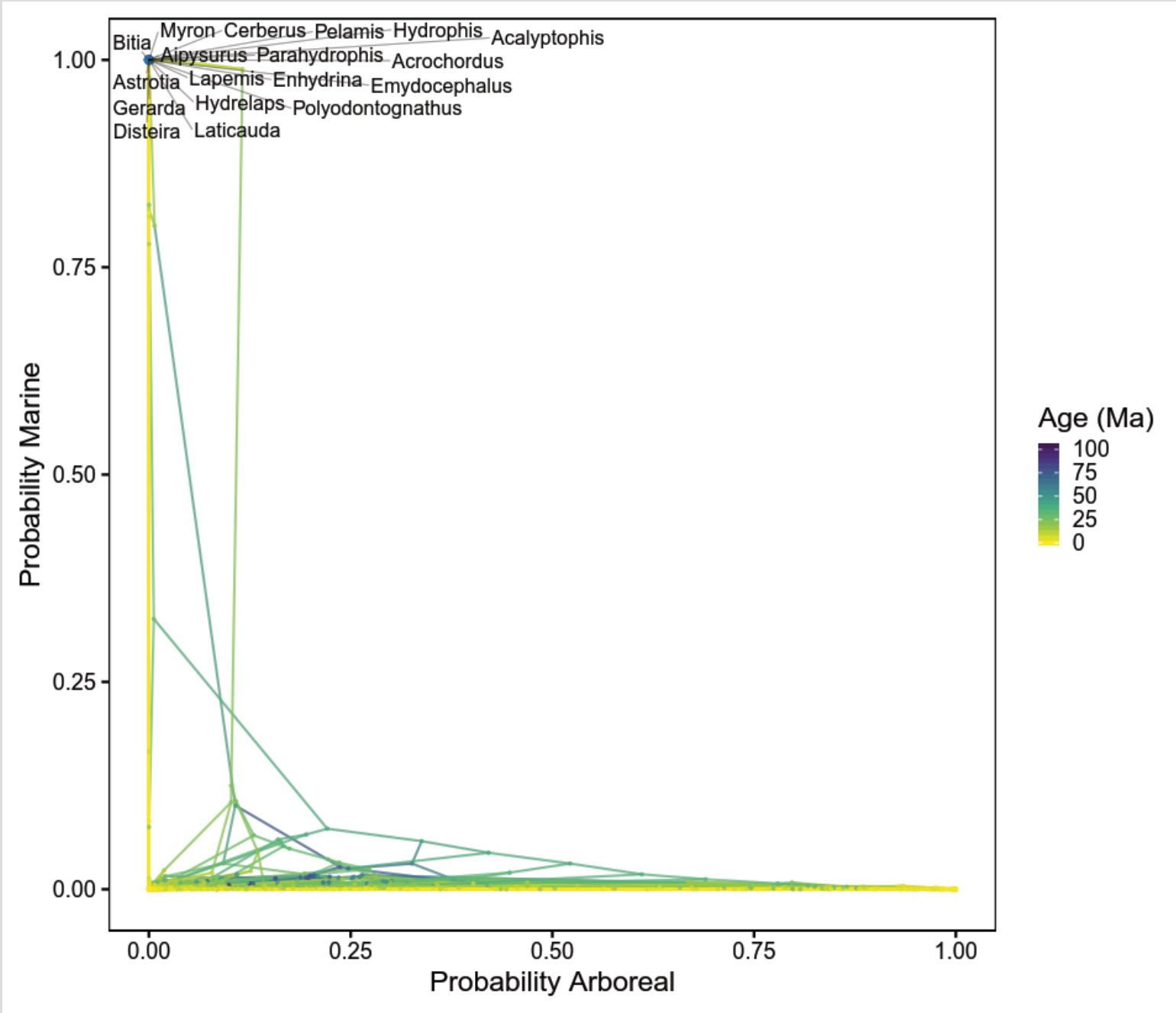

